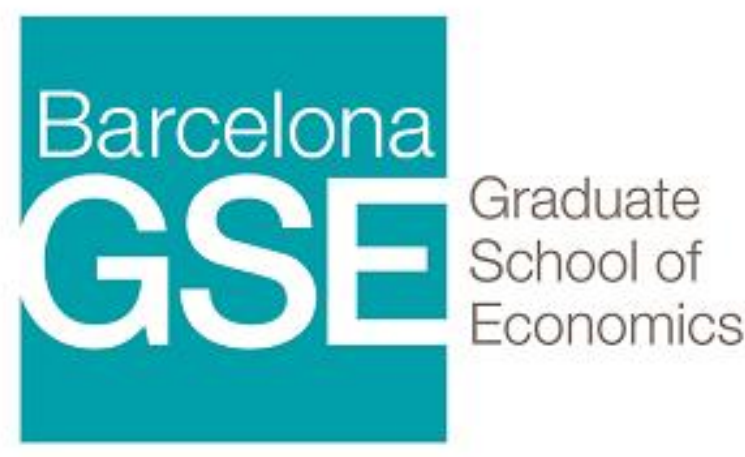

Master Degree in Economics and Finance

"The Impact of the Sharing Economy on Housing Rental Prices: The Case of Airbnb in Barcelona"

\author{
Authors: \\ Marc Agustí, Magnús Ásmundsson, Christof Bischofberger, \\ Pablo de Llanos, Alberto Font, Lucía Kazarian \\ Directors: \\ Larbi Alaoui, Gianmarco León
}


July 2020

\section{ABSTRACT IN ENGLISH (100 words):}

We offer a novel approach to investigate the extent to which the expansion of the sharing economy is responsible for increases in long-term rents and prices on the housing market. Using a panel of quarterly data on newly signed rental contracts and transaction prices in Barcelona from 2015-Q2 to 2018-Q4, we implement a fixed-effects spatial 2SLS method allowing for endogeneity in the variable which measures the presence of Airbnb. We find that a 100-unit increase in the number of Airbnb listings in a given neighborhood induces a $2.1 \%$ increase in rents. We find no indication that Airbnb affects transaction prices.

\section{ABSTRACT IN CATALAN (100 words):}

Oferim un plantejament innovador per investigar fins a quin punt l'expansió de l'economia col-laborativa és responsable de l'augment dels preus de lloguer i de venda d'habitatges. Utilitzant dades trimestrals (de panell) sobre l'import del lloguer mensual dels nous contractes i els preus de compravenda registrats a Barcelona entre el 04/2015 i el 12/2018, implementem un mètode S2SLS d'efectes fixos que permet introduir endogeneïtat en la variable Airbnb. Trobem que, a nivell barri, un augment de 100 unitats en el nombre d'Airbnbs indueix un augment del lloguer del 2,1\%. No trobem evidència de que Airbnb afecti al preu de venda d'habitatges.

KEYWORDS IN ENGLISH: spillovers - externalities - housing markets KEYWORDS IN CATALAN: efectes indirectes - externalitats - mercats inmobiliaris 


\title{
The Impact of the Sharing Economy on Housing Rental Prices: The Case of Airbnb in Barcelona
}

\author{
Marc Agustí, Magnús Ásmundsson, Christof Bischofberger, Pablo de Llanos, \\ Alberto Font, Lucía Kazarian
}

June 8, 2020

\begin{abstract}
We offer a novel approach to investigate the extent to which the expansion of the sharing economy is responsible for increases in long-term rents and prices on the housing market. To this end, we construct a theoretical framework for the housing market that allows for spillover effects between neighborhoods, and other local externalities caused by tourism. The model allows for the short-term housing market devoted to tourism to impact both long-term rental rates and housing prices. Using a panel of quarterly data on newly signed rental contracts and transaction prices in Barcelona from 2015-Q2 to 2018-Q4, we implement a fixed-effects spatial 2SLS method allowing for endogeneity in the variable which measures the presence of Airbnb. We find that a 100-unit increase in the number of Airbnb listings in a given neighborhood induces a $2.1 \%$ increase in rents. We find no indication that Airbnb affects transaction prices.
\end{abstract}

Keywords: Spillovers, externalities, housing markets, Airbnb

Acknowledgements: We are grateful to Larbi Alaoui and Gianmarco Leon for their invaluable advice and encouraging words; and to Javier Barbero, Lung-Fei Lee, Jihai Yu and Sergio Ventura for fruitful discussions and insights. 


\section{Contents}

\begin{tabular}{lll}
\hline & Introduction & 2
\end{tabular}

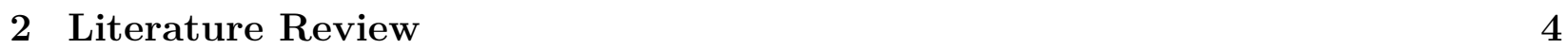

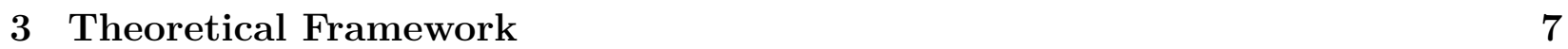

3.1 Intuition . . . . . . . . . . . . . . . . . . . . . . . . . 12

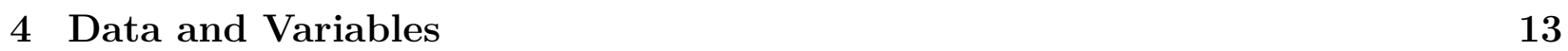

4.1 Neighborhoods . . . . . . . . . . . . . . . . . . . . 13

4.2 Housing Rents and Prices . . . . . . . . . . . . . . . . . . . . . 14

4.3 Airbnb . . . . . . . . . . . . . . . . . . . . . . . . . . 15

$4.3 .1 \quad$ Airbnb Listings Data . . . . . . . . . . . . . . . . . . . . . . . 15

4.4 Descriptive Statistics . . . . . . . . . . . . . . . . . . . . . . . . . 16

$\begin{array}{lll}5 & \text { Empirical Analysis } & 19\end{array}$

5.1 Spatial Analysis . . . . . . . . . . . . . . . . . . . . . . . 19

5.1 .1 Testing for spatial autocorrelation . . . . . . . . . . . . . . . . . 20

5.2 Econometric Model . . . . . . . . . . . . . . . . . . . . . . . . . . . . 20

5.3 Instrumental variable . . . . . . . . . . . . . . . . . . . . . . . . . . . . . . 22

5.3 .1 Validity of the instrument . . . . . . . . . . . . . . . . . . 23

5.4 Implementation of the model . . . . . . . . . . . . . . . . . . . . 25

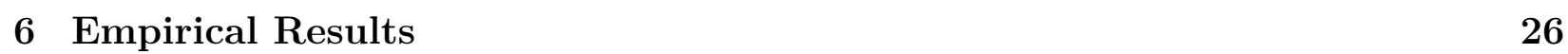

6.1 Impact Measures . . . . . . . . . . . . . . . . . . . . . . . 27

6.2 Interpretation of the results . . . . . . . . . . . . . . . . 28

\begin{tabular}{llr}
\hline 7 & Conclusions & 29
\end{tabular}

\begin{tabular}{|l|l}
\hline A Appendix & 31
\end{tabular}

A.1 Derivations for the Model . . . . . . . . . . . . . . . . . . . 31

A.2 Omitted Proofs . . . . . . . . . . . . . . . . . . . . . . . . 32

A.3 Statistical Tests . . . . . . . . . . . . . . . . . . . . . . 33

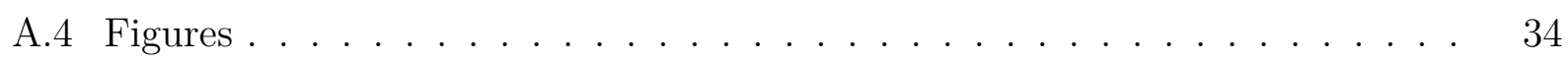

\begin{tabular}{ll}
\hline Bibliography & 41
\end{tabular} 


\section{Introduction}

Peer-to-peer home-sharing platforms such as Airbnb are a new phenomenon which many researchers consider to be responsible for significant disruptions in the housing market. Prior to the introduction of these platforms into the rental market, hotels were the primary supplier of short-term rentals, while residential properties almost exclusively operated on the longterm rental market. The introduction of short-term rental platforms like Airbnb, allows homeowners to choose either to supply on the short-term or the long-term rental markets. As a result, when residential properties are moved to the short-term rental market, the quantity of housing supplied on the long-term rental market decreases, inducing an upward pressure on long-term rents. This simple mechanism was tested empirically by a wide range of research papers. Among those, there is a strong consensus that Airbnb has an overall positive effect on rents in various cities in the United States (Koster et al., 2018; Barron et al., 2018; Horn and Merantea, 2017; Wachsmuth and Weisler, 2018; Calder-Wang, 2019; Lee, 2016), but also in Europe (Garcia-López et al., 2019, Ayouba et al., 2019, Valentin, 2019, Coyle and Yeung, 2016).

Barcelona serves as a prime case study to investigate these effects: there have been substantial growth rates in contractual rental rates, transaction purchasing prices and the number of active Airbnb listings of $27.42 \%, 27.41 \%$ and $29.38 \%$, respectively ${ }^{1}$. Moreover, according to the online source Statista, Barcelona hosts the $6^{\text {th }}$ largest concentration of Airbnb listings in the world. Accordingly, this development sparked our interest in understanding what impact the sharing economy has had on this city's housing market. In brief, we try to answer the following research question: "To what extent is Airbnb responsible for the increase in both contractual rental rates and transaction purchasing prices?", using the city of Barcelona as a case study.

Our main contribution to the existing literature is that we allow for inter-neighborhood spillovers and spatial dependence in the theoretical model and empirical strategy. Suppose we have two neighborhoods: A and B. Intuitively, an increase in long-term rents in A might spill over into the adjacent neighborhood B. Similarly, annoyances specific to short-term rental residents (caused by noisy celebrations or careless maintenance of dwellings, for instance) in A, might generate an externality affecting B. This would reflect the so-called spatial dependence which can lead to spatial autocorrelation in the data. If spatial autocorrelation is not accounted for, the risk of inconsistent estimators arises. Therefore, this paper aims to test how allowing for inter-neighborhood spillovers and spatial dependence influences the predicted positive effect that Airbnb has shown to cause in previous work. Previous literature

\footnotetext{
${ }^{1}$ These growth rates are calculated for the time period 2015-Q2 - 2018-Q4, using this paper's dataset.
} 
does not allow for neighborhood externalities, and this is problematic because not allowing for spatial dependence can lead to inconsistent and biased estimates, and thus incorrect conclusions. Another novelty of this study is that we use quarterly data on contractual rents, as opposed to other studies that use monthly asking prices just for a given time period of each year of the years under study.

Furthermore, we present a novel theoretical model in which we allow for the previously mentioned spatial dependence to exist. The model predicts that a change in the level of Airbnb activity might affect both long-term rents and housing prices. In fact, for a given housing stock size, if negative externalities generated by tourists are sufficiently small, Airbnb can lead to increasing long-term rental prices, although these effects ultimately depend on the specific values the parameters of the model. Thereafter, we empirically test this model and its consequent predictions using a dataset in which neighborhoods are divided into 73 similarlypopulated areas. The data range from 2015-Q2 to 2018-Q4. We implement a fixed-effects spatial 2SLS method allowing for endogeneity in the variable that measures the presence of Airbnb, through an instrumental variable shift-share technique. Google searches for the term "Airbnb Barcelona" predict when listings will appear, and an index that measures the proximity to tourist amenities predicts where Airbnb listings will locate. We account for spatial autocorrelation by including a spatial lag of the dependent variable, using a spatial neighborhood matrix representing the proximity between any two neighborhoods.

Our results show that before allowing for inter-neighborhood spillovers and spatial dependence, Airbnb has a significant positive effect on contractual long-term rents, but no significant effect on transaction prices. Specifically, we find that, for a given neighborhood, a 100-unit increase in active Airbnb listings increases contractual long-term rents by 2.1 percent. However, this model provides biased and inconsistent estimates since the independence assumption does not hold when the sample data is spatially correlated. Indeed, when we allow for inter-neighborhood spillovers and spatial dependence, the average direct effect of a 100-units increase in Airbnb on contractual long-term rents is 1.7 percent. The effect of Airbnb on transaction prices remains non-significant.

Notice that with this model, we are able to disentangle the effect of Airbnb into an ownneighborhood specific effect (direct effect) and a cross-neighborhood effects (indirect effect). In sum, we get that the average total effect on contractual long-term rents is 2.08 percent for a 100-units increase in Airbnb. This shows that Airbnb explains part of the increase in contractual long-term rents and suggest that without allowing for spillovers, the estimates tend to overestimate the average direct effect of Airbnb within a given neighborhood.

The rest of the paper is structured as follows: In section 2 we present a literature review of prior research on the effects of Airbnb on the housing market. In section 3 we present a 
theoretical model that determines the setup of our empirical strategy. Section 4 is a detailed description of the data we use in our research. In section 5 we present an econometric model followed by the empirical findings, in section 6 . Finally, in section 7 we finish with concluding remarks.

\section{Literature Review}

As already stated, there is a strong consensus among scholars studying the impact of the sharing economy on the housing market, that Airbnb has an overall positive effect on rents Koster et al., 2018; Barron et al., 2018, Garcia-López et al., 2019; Horn and Merantea, 2017. Wachsmuth and Weisler, 2018; Ayouba et al., 2019, Valentin, 2019, Calder-Wang, 2019). There are numerous, well-documented causes, that contribute to this positive effect through different mechanisms, which will be outlined below. While the empirical strategies and the geographical specifications vary immensely, overall these findings support one another. Measuring the magnitude of the Airbnb effect on the residential housing market, we expect to observe differences across cities depending on city-specific factors such as city density, geographical characteristics, characteristics of the tourism industry, and conditions of the housing market prior to the introduction of this new technology. These differences also depend on how well researchers isolate and capture the effects of Airbnb on the housing market and the methods employed.

The majority of existing literature studies the effect of Airbnb in the US. In a detailed nationwide study, Barron et al. (2018) employ an instrumental variable estimation strategy to assess the impact of home sharing on residential housing prices and rents. They find that a $1 \%$ increase in Airbnb listings lead to a $0.018 \%$ increase in rents and a $0.026 \%$ increase in house prices at the median-occupancy rate zip-code. They measure neighborhoods' "touristiness" using the number of establishments in the food services and accommodations industry.

Instead of looking at the impact of Airbnb at the nationwide level, most researchers have focused their studies on individual cities. In the case of Los Angeles, Lee (2016) finds that Airbnb leads to an increase in citywide rents and decreases affordable housing supply, while Airbnb also spurs displacement, gentrification and segregation. He identifies two interconnected mechanisms which contribute to these distortions. First, the conversion of residential housing to quasi-hotel rooms leads to a real increase in city-wide rents. This effect is mostly concentrated in affluent or gentrifying neighborhoods in the city's center. Second, the overpowering incentive homeowners face when they are able to rent out quasi-hotel rooms for a cheaper prize than actual hotel rooms, while earning a large premium over the residential market, causes displacement of residents, gentrification and segregation in the city as 
homeowners move from the long-term rental to the short-term rental market. Another study on Airbnb in Los Angeles found that a restrictive legislation on short-term rentals reduced Airbnb listings by $50 \%$ and as a result decreasing both housing prices and rents by $3 \%$ (Koster et al. 2018). Therefore, the case of Los Angeles demonstrates what we would expect: the overall effect of "hotelization" causes a decrease in the supply of residential housing, which positively affects rents and causes displacement of residents while restrictive legislation to some extent can be used to combat the effects on housing and rent.

We observe similar effects in other American cities such as New York and Boston. In a study on the rental market in Boston, Horn and Merantea (2017) attempt to seperate the supply and demand effects on home sharing caused by Airbnb. They apply a hedonic estimation to assess the affect of Airbnb on asking rates in the next time period and include fixed effects (FEs) at the census track level, comparisons being made over six-month periods. Their findings indicate that a one standard deviation increase in Airbnb listings is associated with a $4 \%$ increase in asking rents in Boston. Wachsmuth and Weisler (2018) use another method to estimate the effects of short-term rentals in their New York study. Comparing two trends, the percentage of housing revenue that flows through Airbnb, and the percentage of median rent which an average full-time Airbnb property earns, allows them to approximate the non-observables which account for the rent gap, i.e. potential ground rent and capitalized ground rent. So-called "post-gentrified" neighborhoods are found to be most impacted by the introduction of Airbnb. These are areas that have already been pervasively restructured by capital over the past few decades and transformed into wealthy neighborhoods. Homeowners in these neighborhoods have capitalized on the rent gap created by the introduction of short-term rentals by ceasing long-term rental and entering the short-term rental market. Both Wachsmuth and Weisler (2018) and Koster et al. (2018) demonstrate that Airbnb has disproportionate effects on different neighborhoods within cities, the strongest effect typically observed in city centers.

Although the vast majority of literature that studies the effect of Airbnb on long-term rents focuses geographically on the United States, there is a growing appetite for investigating these effects in Europe. Ayouba et al. (2019) estimate hedonic equations for eight cities in France using a data-base of 136,133 dwellings in 2014-2015. The authors propose a spatial heteroskedasticity and autocorrelation consistent estimator à la Kelejian and Prucha (2007) and apply this method to their spatio-temporal dataset. They show that the density of Airbnb rentals positively affects rents in Lyon, Montpellier and Paris $(0.39,0.40$ and 0.53 percent respectively), while they find insignificant effects in the other five cities. Furthermore, they investigate "professional" Airbnb rentals (rentals whose hosts have more than one lodgings and/or more than 120 days of reservations per year). Here, they find an even stronger effect 
on rents in Paris (1.24 percent) and significant results for Marseille, but do not find significant results in Lyon and Montpellier. Coyle and Yeung (2016) take a different approach and look at the Airbnb effect on hotels and rental rates in 14 European cities. Due to data constraints they only study rental rates in Germany and the United Kingdom (from 2005-2016 and 2011-2016 respectively) using aggregated city level panel data. While they find no significant effects for cities in Germany, in the United Kingdom a 1 percent increase in the number of Airbnb activities is associated with an increase of 0.22 percent.

Arguably the most relevant study of the effects of Airbnb to our project is the one from Garcia-López et al. (2019), who measure the effect of Airbnb on rental rates in the city of Barcelona. The authors use a dataset from Inside Airbnb containing 21 data points from 2015 to 2018 on Airbnb listings and all posted ads for rentals and sales that were active each December in the 2007-2017 period on the biggest real estate platform in Spain, Idealista. This dataset contains the exact location, the posted rent or price and the size of all available properties. Their theoretical model predicts that homeowners benefit from Airbnb either because they receive the short-term rental rate (higher than the long-term rental rate) through renting on Airbnb, or because Airbnb increases the long-term rental rate itself. However, long-term residents suffer higher rents and negative externalities caused by tourism. The empirical strategy is threefold and includes i) a panel fixed-effects model with neighborhood-specific time trends, ii) an instrumental variable shift-share approach (using tourist amenities and Google searches as instruments for the time and location of Airbnb listings), and iii) an event-study design. Through these methods, Garcia-López et al. (2019) find that for the average neighborhood in Barcelona, Airbnb has caused rents prices to increase by 1.9 percent, while transaction (posted) prices have increased by 5.3 (3.7) percent. For neighborhoods where Airbnb activity was highest the effects were even more pronounced: rents increased by 7 percent and transaction (posted) prices increased by 19 (14) percent in these neighborhoods.

While the discussed literature above encapsulates most of the literature directly related to this paper's research question, there is still a wide range of literature that is only indirectly related, looking at welfare effects of Airbnb (Filippas et al., 2019; Calder-Wang, 2019, Horton, 2015), regulation (Valentin, 2019) or how Airbnb affects the hotel industry (Farronato and Fradkin, 2018; Zervas et al., 2017). Though results presented in this paper cannot be directly compared to this line of research, we can make inferences about the potential implications our findings have on welfare effects. Calder-Wang (2019) for example uses an integrated housing market model to specify demand and supply both in the long-term and in the short-term rental market for New York City. Overall, they find that renters suffer a welfare loss of 178 million US Dollars per year, concentrated around renters who are white, educated and in 
high-income brackets. Similarly, Filippas et al. (2019) show that sharing economy platforms in general increase ownership surplus. They do not find this empirically for the housing market, but rather theoretically for any durable good. Valentin (2019) investigates the effect of short-term rental regulation on Airbnb listings in New Orleans. The author shows that regulation increased the probability of Airbnb listing closure throughout the entire city due to increased costs faced by agents. This effect is also valid along the internal margin. Effects were most pronounced in neighborhoods facing tighter regulations, showing that regulation is successful in changing the leasing behavior of agents. Agents in adjacent neighborhoods on the other hand profit from spillovers of short-term rental guests.

Because Airbnb listings can be viewed as substitutes to hotels, many researchers also focus on the effects on hotel revenue and prices. For example, Farronato and Fradkin (2018) present a model of competition between flexible and dedicated sellers, like peer hosts or hotels, who provide differentiated products. The estimation of this model reveals that welfare gains from Airbnb are concentrated in high-demand places (New York) and during peak demand periods (New Years Eve), as peer hosts are responsive to market conditions and expand supply as hotels fill up, keeping hotel prices low. Zervas et al. (2017) on the other hand make use of the variation of Airbnb introduction dates in different areas in Texas to construct a difference in differences framework. They reach the conclusion that the impact of Airbnb on hotel revenue is in the negative $8-10 \%$ range. However, they also find that this impact is nonuniform: hotels in the high end of the price distribution, catering mainly business travelers, are less affected. Similarly to Farronato and Fradkin (2018), they find that the price response is highest in peak demand periods, as peer-to-peer platforms enable instantaneous supply to scale to meet demand.

\section{Theoretical Framework}

In this section, we build on Garcia-López et al. (2019), as well as Barron et al. (2018) to develop a framework that allows us to study the effects of the short-term housing market on the long-term housing market.

Let $S_{n} \in[0,1]$ be the stock of (homogeneous) housing units owned by absentee homeowners in neighborhood $n$, where $n \in\{1, \ldots, N\}$. Absentee homeowners choose between two mutually exclusive options: either to rent out their housing units to local residents on the long-term rental market, receiving a monthly rent of $R_{n} \in \mathbb{R}^{+}$, or rent out to tourists on the short-term market, receiving a monthly rent of $T_{n} \in \mathbb{R}^{+}$. Furthermore, there exists an individual-specific (non-pecuniary) cost $c_{j} \in \mathbb{R}^{+}$to rent in the short-term market. This cost reflects the inherent uncertainty of running an Airbnb business and relates to the 
homeowner's level of risk-aversion. We assume that $T_{n}>R_{n} \forall n$ and that the probability distribution of $c_{j}$ is the same for all neighborhoods, i.e. $f\left(c_{j}\right) \perp n$. If $T_{n}-c_{j} \leqslant R_{n}$, the owner will enter the long-term rental market; while if $T_{n}-c_{j}>R_{n}$, the $\operatorname{cost} c_{j}$ will pay off and they will rent short-term.

Proposition 3.1. In equilibrium, it must be that there is a marginal owner which is indifferent between running an Airbnb business or renting in the long-term market to a resident.

Proof: See appendix A.2

We denote the cost assumed by this marginal homeowner as $c_{j}^{*}$. Additionally, we provide an illustration of the distribution of homeowners over costs in Figure 1. As it can be seen, in equilibrium, those owners assuming a cost lower than $c_{j}^{*}$ will rent to tourists, while those assuming cost larger than $c_{j}^{*}$ will rent to local residents. For a given neighborhood $n$, we denote the equilibrium $\operatorname{cost}$ as $c_{j, n}^{*}$ so that:

$$
T_{n}-c_{j, n}^{*}=R_{n}
$$

Note that, by making $c_{j}^{*}$ dependent on $n$, we are simply saying that, although the distribution of $c_{j}$ is equal across neighborhoods, the proportion of owners renting in the short-term market can be different across neighborhoods:2

Figure 1: Distribution of homeowners over costs

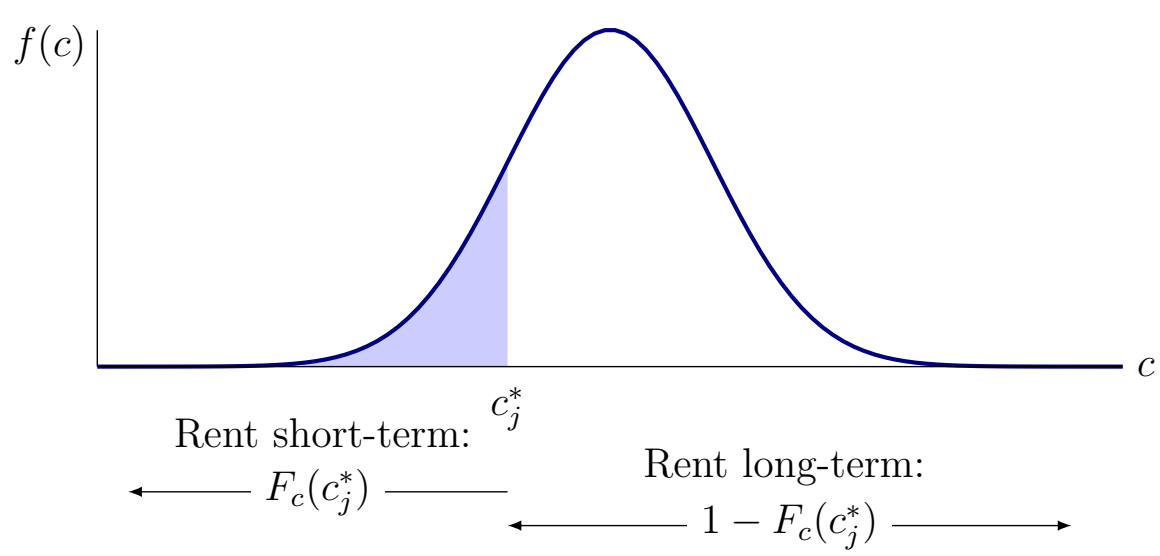

Let $\alpha>0$ be a parameter reflecting the extent to which an individual living in neighborhood $n$ is damaged by the presence of Airbnb in their neighborhood. Let $\gamma \in[0,1)$ be the degree of inter-neighborhood dependence generated by spatial externalities, which is assumed to be identical for all neighborhoods. Finally, we define $a_{i, n}$ as an idiosyncratic term

\footnotetext{
${ }^{2}$ Later, we will relax this assumption to make computations less cumbersome.
} 
representing individual $i$ 's preference for living in neighborhood $n$. Accordingly, $U_{i, n}$ is the utility of an individual $i$ living in neighborhood $n$ under a rental agreement, and it is given by the following expression:

$$
U_{i, n}=Y_{i}-R_{n}+a_{i, n}-\alpha\left[F_{c}\left(c_{j, n}^{*}\right)+\gamma \sum_{s \neq n} \omega_{s, n} F_{c}\left(c_{j, s}^{*}\right)\right]
$$

where $Y_{i}$ is income, $F_{c}\left(c_{j, n}^{*}\right)$ is simply the cumulative distribution function of $c_{j}$ evaluated at $c_{j, n}^{*}$, and therefore $\alpha F_{c}\left(c_{j, n}^{*}\right)$ represents the extent to which this individual is harmed by the presence of Airbnb in their neighborhood. Similarly, the idea of spatial externalities emerging from other neighborhoods, i.e. the manner in which a neighborhood $n$ is affected by the presence of Airbnb in other neighborhoods, is captured by the term $\alpha \gamma \sum_{s \neq n} \omega_{s, n} F_{c}\left(c_{j, s}^{*}\right)$. Here, $\omega_{s, n} \in(0,1) \forall s \neq n$, where $s \in\{1, \ldots, N\}$, represents the connectivity (or spatial proximity) between area $n$ and its neighbor regions $s \neq n$, and it is assumed to be nonstochastic and finite. Moreover, $\sum_{s \neq n} \omega_{s, n}=1 \forall n$. As a consequence, the more connected a region $n$ is to its neighboring regions, the more it is affected by spatial externalities. To conclude, recall that the initial parameter $\alpha$ is constant and independent of any other variable. Thus, it represents the degree to which tourism negatively affects our individual $i$ independently of the source of such externalities (either in neighborhood $n$ or any other areas, denoted by $s$ ).

In equilibrium, we normalize the marginal resident's utility to $U_{i, n}=Y_{i}$ so that they are indifferent between living in neighborhood $n$ or somewhere else. Therefore,

$$
R_{n}\left(a_{i, n}^{*}\right)=a_{i, n}^{*}-\alpha\left[F_{c}\left(c_{j, n}^{*}\right)+\gamma \sum_{s \neq n} \omega_{s, n} F_{c}\left(c_{j, s}^{*}\right)\right]
$$

where $a_{i, n}^{*}$ denotes the preference term of our marginal resident, and thus equation (3) describes their willingness to pay to live in neighborhood $n$. We provide an illustration of the distribution of neighbors over preferences in Figure 2.

In equilibrium, all the markets in neighborhood $n$ must clear, meaning that no housing unit can be left vacant in either market. Equation (4) formalizes the market-clearing condition:

$$
S_{n}\left[1-F_{c}\left(c_{j, n}^{*}\right)\right]=1-F_{a}\left(a_{i, n}^{*}\right)
$$

Equation (4) simply says that the number of residents living in neighborhood $n$ under a rental agreement must equal the number of available housing units actually rented by absentee homeowners (the left-hand side of the equation). Suppose all of the housing stock in neighborhood $n$ were owned by absentee homeowners, i.e. $S_{n}=1$. Then, the proportion 
Figure 2: Distribution of neighbors over preferences

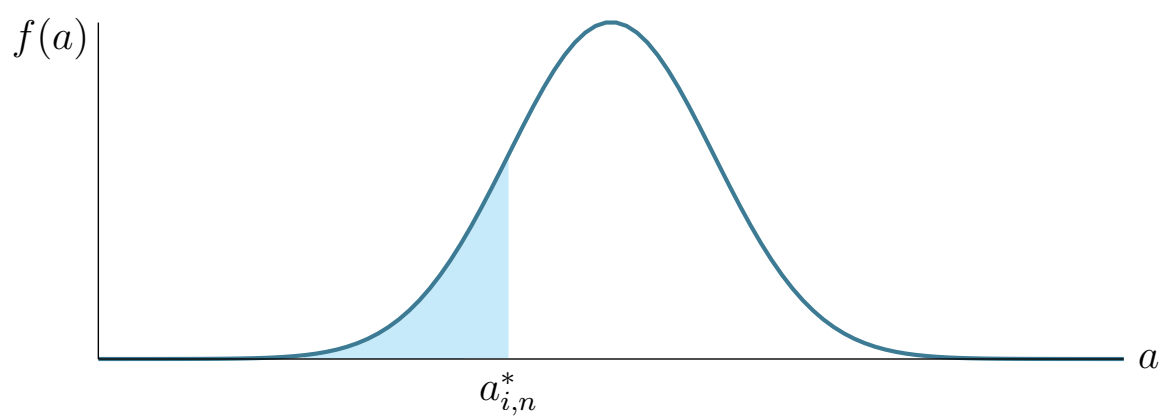

Live somewhere else:

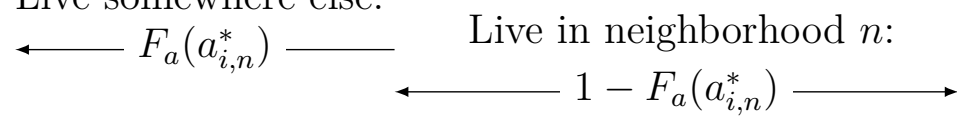

of individuals living in $n$ under a rental agreement would equal the proportion of absentee homeowners offering their properties in the long-term market, since all the dwellings in neighborhood $n$ would be owned by absentee homeowners. On the contrary, if $S_{n}=0$, the number of dwellings offered by absentee home-owners (in any housing market) must equal zero: $1-F_{c}\left(c_{j, n}^{*}\right)=0$, irrespective of the value of $c_{j, n}^{*}$. Likewise, the number of residents paying rent in $n$ must equal zero, and thus $F_{a}\left(a_{i, n}^{*}\right)=1$. That is, every resident on the rental market would be required to move elsewhere.

Without loss of generality, to make computations less cumbersome, let us assume that $c_{j}$ and $a_{i}$ are independent and uniformly distributed from zero to one: $U \sim(0,1)$. Let us also assume that $c_{j, n}^{*}=c_{j, s}^{*}=c_{j}^{*} \forall n \neq s$. Intuitively, this implies that the proportion of homeowners renting to the short-term market is the same across all neighborhoods. This is far from ideal, though irrelevant for our purposes 3 . We only need to have an expression that shows us the relationship between the proportion of homeowners that decide to rent in the short-term market $\left(c_{j}\right)$ and the housing rent prices in the long-term market $(R)$. Further, note that we are interested in understanding how different spillovers affect these long-term rents. The aforementioned assumption is therefore inconsequential to our analysis and the interpretation of the model.

Then, after making these assumptions, by combining (1), (3) and (4) we get an expression for $c_{j}^{*}$, which describes the cost assumed by our marginal homeowner when we are in equilibrium:

$$
c_{j}^{*}=\frac{S_{n}-1+T_{n}}{S_{n}+1-\alpha(1+\gamma)}
$$

\footnotetext{
${ }^{3}$ The aim of the model is to study how the presence of Airbnb affects prices, but we are not directly interested in the levels.

${ }^{4}$ All the derivations for the model can be found in appendix A.1
} 
From equation (5), we get the following results: First of all, $c_{j}^{*}$ depends positively on $T_{n}$, the monthly rent that a homeowner would get by renting out a dwelling in $n$ 's short-term market. Note that $T_{n}$ reflects the attractiveness of a neighborhood. For this reason, if $T_{n}$ $<1-S_{n}$ there would be no short-term platforms in neighborhood $n$. Indeed, the strict positiveness of $c_{j}^{*}$ requires that $T_{n} \geq 1-S_{n}$. Second, $c_{j}^{*}$ will also depend positively on $\alpha$. This implies that for a positive increase in the negative externalities generated by tourism, the proportion of homeowners renting in the short-term market will also increase. The intuition for this is the following: as the degree to which residents are harmed by negative externalities increases (i.e. as $\alpha$ increases), more of them will decide to abandon their neighborhood $(n)$, reducing the demand for long-term housing in $n$. As a result, $R_{n}$ will suffer a downward pressure, increasing the relative profitability of the short-term rental market for homeowners. Note that this effect would be aggravated by a positive $\gamma$, given that if the degree of interneighborhood dependence generated by spatial externalities increases, our individual $i$ would also be harmed by the tourism activity that takes place in close neighborhoods. Therefore, they will be more likely to abandon their neighborhood to one which does not have a large proportion of homeowners renting in the short-term market and one that is also far away from neighborhoods which have a large amount of short-term platforms. This process is what is generally known as gentrification or, in this particular case, Airbnb-induced gentrification!5.

One of our contributions to the research on the housing market appears in what follows. We have considered short-term rents to be positively correlated across neighborhoods. For this reason, we define $T_{n} \equiv A_{n}+\phi \sum_{s \neq n} \omega_{s, n} T_{s}$, where $A_{n} \in \mathbb{R}^{+}$is a measure of local amenities which are valued by tourist ${ }^{6}$. Here, $\phi \in[0,1)$ measures the connectivity of short-term rents across neighborhoods. Therefore, we assume that the short-term rents in neighborhood $n$ depend on its level of attractiveness to tourists as well as the short-term rents of its closest neighborhoods. That is, we allow for spatial spillovers to exist.

In what follows, we define $T_{n}^{*}$ as the $n$ 's short-term rent in steady-state equilibrium. For simplicity, let us assume that $T_{n}^{*}=T_{s}^{*}=T^{*} \forall n \neq s$. Again, this is far from ideal but fairly useful for our purposes. Then, $c_{j}^{*}$ can be rewritten as

$$
c_{j}^{*}=\frac{S_{n}-1+A_{n} /(1-\phi)}{S_{n}+1-\alpha(1+\gamma)}
$$

Intuitively, as $\phi$ increases $c_{j}^{*}$ goes up. This is because the higher the connectivity of shortterm rents across neighborhoods $(\phi)$, the higher $c_{j}^{*}$ will be for a given rent-level in all the neighborhoods. Essentially, when $\phi$ increases, given that prices are positively correlated

\footnotetext{
${ }^{5}$ See Wachsmuth and Weisler (2018).

${ }^{6}$ Consider $A_{n}$ as a scalar measuring the attractiveness of neighborhood $n$ according to its different tourist amenities (we will get back to this point when discussing the shift-share IV in section 5.3).
} 
across neighborhoods, homeowners will have a stronger incentive to rent in the short-term market to tourists. This captures the idea of general spatial effects in rents.

\subsection{Intuition}

In equilibrium, it can easily be shown that

$$
R_{n}=\left[S_{n}-\alpha(1+\gamma)\right] c_{j}^{*}(\phi)-\left(S_{n}-1\right)
$$

Therefore, for a given increase in $c_{j}^{*}$, we can differentiate two effects working in opposite directions. On the one hand, as the supply of housing units into the long-term market decreases by $\Delta c_{j}^{*}$, ceteris paribus, this drop in the supply of housing units translates into an increase in rents of $S_{n} \Delta c_{j}^{*}$. On the other hand, a marginal increase in the proportion of homeowners renting short-term implies a higher level of externalities emerging from tourism, which decreases the demand of housing and thus pushes rents downwards by $\alpha(1+\gamma) \Delta c_{j}^{*}$. Consequently, the net effect of a marginal increase in $c_{j}^{*}$ on the long-term rents will depend on the stock of housing units and the level of externalities generated by tourism. Notice that the strict positiveness of $c_{j}^{*}$ in equations (5) and (6) only implies that $S_{n}+1>\alpha(1+\gamma)$, and thus 1 is an upper bound for $\alpha$. Therefore, we cannot conclude that a marginal increase in $c_{j}^{*}$ will cause an increase in $R_{n}$. Only if $S_{n}>\alpha(1+\gamma)$, a positive change in $c_{j}^{*}$ will induce an increase in long-term rental rates. In other words, rents will rise if the negative externalities generated by tourists are small enough given the size of the neighborhood, which is reflected by $S_{n}$. Another key feature of equation (7) is that, through $c_{j}^{*}, R_{n}$ will also be affected by the degree of connectivity across the different neighborhoods' short-term rental markets (i.e. $\phi)$. This reflects, again, the relevance of spatial spillovers.

From the above equations, it follows that in a steady-state market equilibrium the price of a dwelling $(P)$ must be defined by the present value of the future stream of income received by an average absentee homeowner. That is, in neighborhood $n$, the price of a housing unit is defined as:

$$
P_{n}=\sum_{t=0}^{\infty} \delta^{t}[\underbrace{\left(1-c_{j}^{*}\right) R_{n}}_{\begin{array}{c}
\text { Long-term } \\
\text { market }
\end{array}}+\underbrace{\int_{0}^{c_{j}^{*}}\left(T_{n}-c\right) d c}_{\begin{array}{c}
\text { Short-term } \\
\text { market }
\end{array}}]
$$

where $\delta$ is a monthly discount factor. However, note that given that we assumed that $T^{*}$ and $c_{j}^{*}$ are both equal in all neighborhoods we must also have that $R_{n}=R_{s}=R^{*} \forall n \neq s$. As a result, we will have the following expression for the price (which will be the same across all 
neighborhoods, thus abstracting from more complicated results):

$$
P^{*}=\frac{1}{1-\delta}\left[R^{*}+\frac{\left(c_{j}^{*}\right)^{2}}{2}\right]
$$

From Equation (9) we can get a very intuitive result: the effect of Airbnb activity on housing prices is higher than in long-term rents, which makes sense given that a part of the housing stock will be rented at a monthly price of $T_{n}-c_{j}$ that is higher than $R_{n}$.

To sum up, the model gives us two useful intuitions. First, the model explains how the level of Airbnb activity can affect both long-term rents and housing prices, taking into account the fact that $c_{j}^{*}$ is a function of externalities: $\alpha$ and $\gamma$. Second, through $\phi$, the theoretical setting takes into account the fact that rents may be positively correlated across neighborhoods (the spillover effect). These are the key ingredients of the model and we will demonstrated that it is crucial to take them into account account in order to attain any important conclusions.7 Finally, the model predicts that a change in the level of Airbnb activity might affect both long-term rents and housing prices. In fact, for a given housing stock size, if negative externalities generated by tourists are sufficiently small, Airbnb can lead to increasing long-term rental prices. These effects ultimately depend on the parameter values. Accordingly, the empirical analysis will be guided by the results obtained in equations (6), (7) and (9).

\section{Data and Variables}

\section{$4.1 \quad$ Neighborhoods}

Our geographical unit of analysis is the "neighborhood" as defined by the Barcelona City Council..$^{8}$ A criterion for creating this delimitation was ensuring a high degree of in-neighborhood homogeneity and inter-neighborhood heterogeneity, as well as guaranteeing that neighborhoods are similarly populated. Accordingly, we believe this classification is an appropriate neighborhood definition. Moreover, their size is sufficient to generate meaningful results: there are 73 neighborhoods with an average of 22,421 inhabitants.

\footnotetext{
${ }^{7}$ We show that the spillover effect we have introduced in the model is a key determinant of the evolution of prices over time.

${ }^{8}$ This delimitation started with the project La Barcelona de los Barrios, which began in 2004 with the objective of establishing a delimitation of the City of Barcelona in significant neighborhoods, both from the urban-planning and a social point of view.
} 


\subsection{Housing Rents and Prices}

The data on rents and transaction prices are both obtained from the Barcelona's City Hall Open Data Service. Transaction prices are defined as the price of the dwellings, in thousands of euros, which appears in the deeds of sales registered in the Property Registry. We consider this data in terms of euros per square meter $\left(€ \mathrm{k} / \mathrm{m}^{2}\right)$. On the other hand, rents are defined as the average monthly rent per square meter $\left(€ / \mathrm{m}^{2} / \mathrm{month}\right)$. This statistic measures contractually agreed prices and has a census character: it draws on the the filings of deposits of all the rental contracts lasting more than one year during the period considered. These data are released by Incasòl..$^{9}$ Therefore, this variable reflects the current state of the prevailing market prices. As Figure 3 shows, rents of newly signed contracts is a good measure of prevailing rents for new tenants as they follow parallel trends with asking prices during the period we study. That is, the time paths of residential agreed and asking rents for Barcelona show similar trends.

Figure 3: Evolution of long-term rents in Barcelona

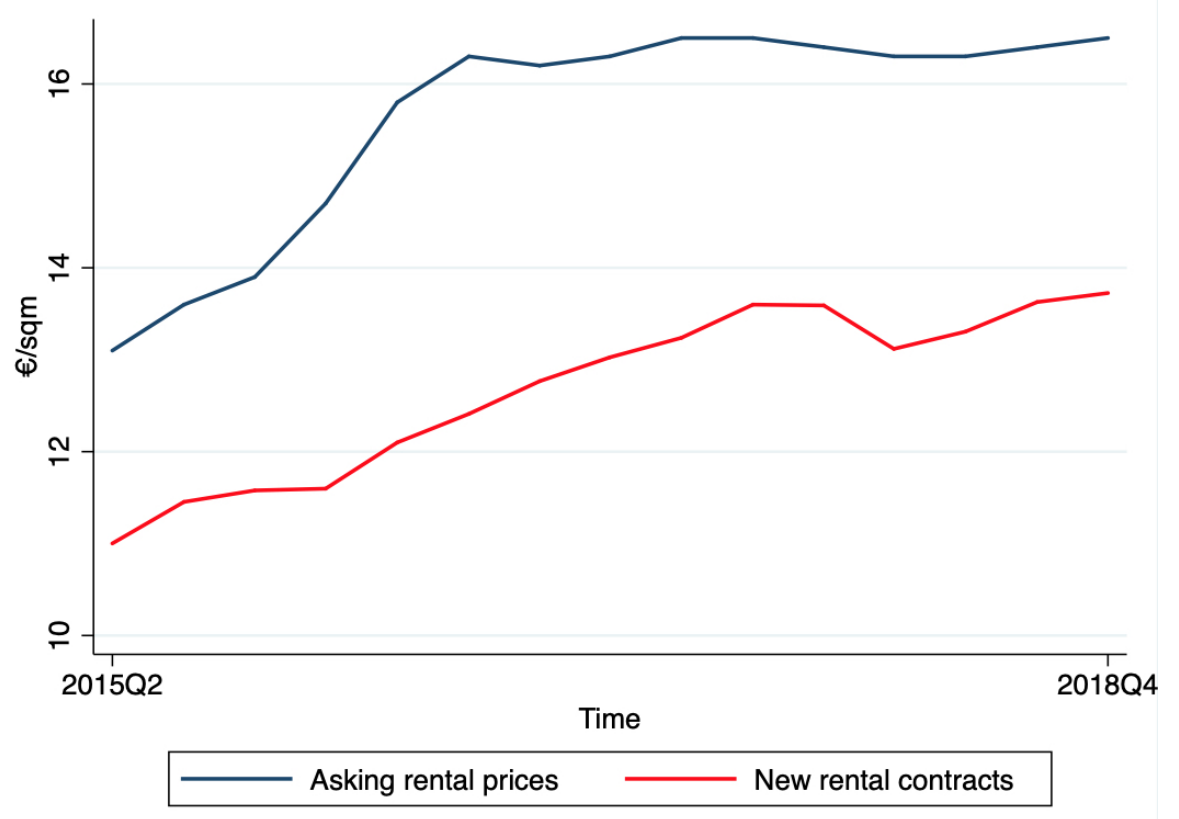

Likewise, we argue that contractual rents are a good proxy for the market rental dynamics. What is more, we also believe they measure prices more precisely than posted prices since bargaining is usually involved in the process of renting a dwelling.

\footnotetext{
${ }^{9}$ Incasòl is the Catalan Land Management Institute, which is subordinate to the Ministry of Territory, Sustainability and Housing. It is in charge of managing all the urban planning matters that are the responsibility of the Government of Catalonia. Accordingly, all the homeowners who sign a rental contract must deposit the rental agreement in Incasòl within a period of two months or less.
} 


\subsection{Airbnb}

The platform was established in Barcelona around 2010 and its presence experienced a rapid increase up until mid-2018, when Barcelona's town-hall passed a law limiting the creation of new Airbnb listings. This high (and increasing) presence of Airbnb in Barcelona has not gone unnoticed. Indeed, the local government has tried to limit the platform's activity in the city several times. As early as 2014, the town hall conjectured that the platform's activity should be considered illegal and tried to impose a fine to Airbnb. However, this fine was then dismissed by the courts.

As for the data, we take it from the publicly available website Inside Airbnb, which is a non-commercial source that stores data on Airbnb listings from many different cities around the world. There we can find that the current number of Airbnb listings fluctuates around $18,000,48.7 \%$ of which are entire homes, $50.2 \%$ private rooms and a negligible $1.1 \%$ shared rooms. Additionally, we can also see that $65.3 \%$ of the hosts own multiple advertised properties.

\subsubsection{Airbnb Listings Data}

We use data on Airbnb listings for each quarter from 2015-Q2 to 2018-Q4. We mainly use two files from Inside Airbnb: a file that has information on the the daily availability of each listing since 2015, and a file that contains monthly information on prices, number of reviews, neighborhoods, locations and types of rooms (entire homes, private rooms or shared rooms).

To analyze information on the monthly active listings in Barcelona for every year since 2015, the first file is reshaped in Stata. Listings that are not active during a quarter are not considered for our analysis, but if they are active again for a different month we make sure to include them again. The next step is to use the detailed file on each listing in order to attach the neighborhood to the file we have just reshaped. Additionally, we also attach to each listing its corresponding room-type. Now we are able to locate how many Airbnb listings were active each month in every neighborhood in Barcelona and differentiate between different types of listings. However, we have to point out the following issues we have faced. 1086 listings observations have no neighborhood classification. These listings are omitted in our analysis. In total, we analyse 229,171 private rooms, 279,081 entire homes and 4,859 shared rooms. 185 listings have no room-type classification, and together with shared rooms, these observations are also dropped from the data. Finally, we only keep private rooms in the data if the homeowner is advertising more than one property in Airbnb, since we interpret this as a commercial use of the platform. 10 All the private rooms with only one

\footnotetext{
${ }^{10}$ We do this because someone who is advertising multiple private rooms can be interpreted as someone
} 
homeowner (76,572 observations) are dropped from the sample. By simplifying the data on Airbnb listings as we have done, we only consider listings that can have an actual impact on the housing market and avoid considering listings irrelevant to our analysis.

\subsection{Descriptive Statistics}

First, we look at the distribution of Airbnb listings in Barcelona for 2018-Q2 and how this distribution has evolved since 2015-Q2. In Figure 4a, we can observe that the largest number of Airbnb listings is located in the city center, and expands to the south of Barcelona, specially to the coastal zone and the west-side area. The former include neighborhoods such as La Dreta de l'Eixample, el Raval, la Sagrada Família and the Gothic quarter.

If we focus on the evolution of Airbnb listings since 2015 (Figure 4b), we notice that the expansion has happened in the same neighborhoods where we find the largest amount of Airbnb listings.

Figure 4: Airbnb listings in Barcelona (2018-Q2) and its evolution since 2015-Q2

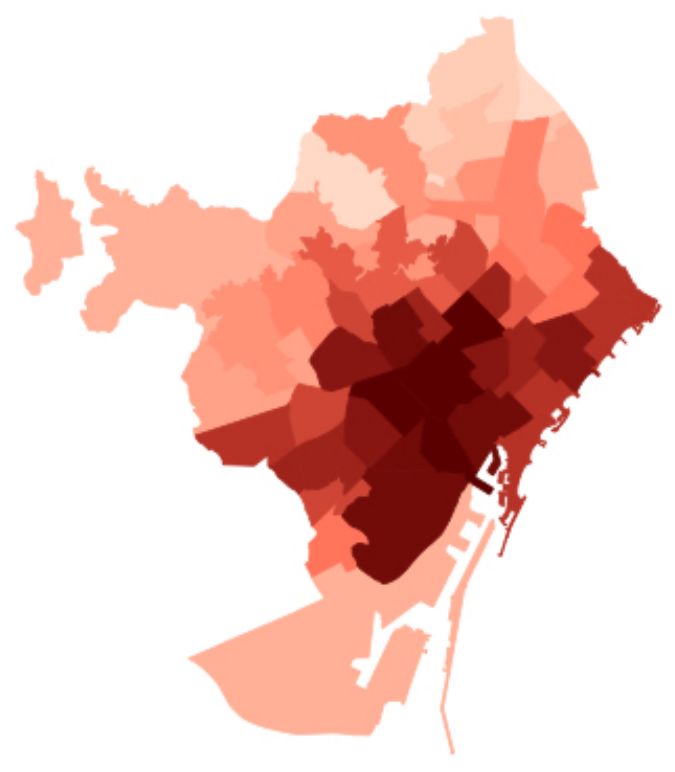

(a) Airbnb listings

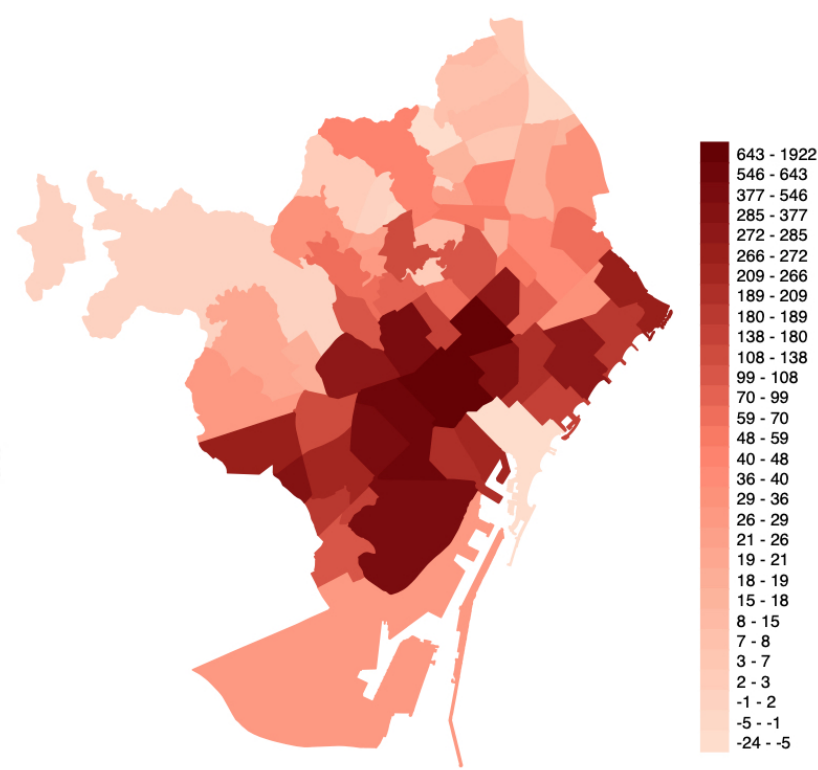

(b) Evolution of Airbnb listings

With regards to the density of Airbnb 11 , in Figure A.2a we can observe the density of

who is advertising an entire home. Whenever owners only advertise a single private room, we assume these types of listings have no significant impact on the housing market.

${ }^{11}$ The density in a neighborhood is defined as the total number of Airbnb listings per every 1000 dwellings. 
Airbnb in the city of Barcelona in 2018-Q2. Further, we can also observe which areas have grown the most in terms of density by comparing the numbers in 2018-Q2 to those in 2015Q2 12 Similarly, we find that Airbnbs are more numerous in the districts around the city centre: la Sagrada Família, El Port Fienc and Vila de Gràcia, as well as the neighborhood of Poblenou, which is located by the beach. The neighborhoods in the northeast of Barcelona have a lower level of Airbnb density, which includes the districts of Nou Barris and Sant Andreu. Turning our focus back to the evolution of Airbnb density, we can see that the same areas which have an already high density also experience the highest absolute growth in Airbnb density.

Regarding short-term rents, we find that the highest average contract value is $2034 € /$ month, and it is found in the neighborhood of Pedralbes in 2015-Q3. On the contrary, the lowest average contractual rent is $142 € /$ month, and it is found in Baró de Viver in 2016-Q1. Turning our attention to prices per square meter, we observe that the highest contracts are at $20.61 € / m^{2}$, and we find them in Vallvidrera, el Tibidabo i les Planes in 2017-Q3. The lowest values are at $3.18 € / \mathrm{m}^{2}$, and we find them in Baró de Viver in 2016-Q1 (as before). For the whole territory studied, the mean new rental contract in both units of measurement are $793.9 €$ and $11.97 € / \mathrm{m}^{2}$ (with standard deviations of $311.2 €$ and $3.71 € / \mathrm{m}^{2}$ ), respectively. We plot the distribution of rents in the city of Barcelona both in terms of $€$ and $€ / m^{2}$ for 2018Q2 ${ }^{13}{ }^{14}$ There is not a big difference between both units of measurement, as we can clearly observe that the highest new contracts are signed in the upper west-side of Barcelona and the beach-side: the neighborhoods of Sarrià, Pedralbes, Les Tres Torres, La Dreta de L'Eixample, La Barceloneta and Diagonal Mar i el Front Marítim del Poblenou. Moreover, by looking at the growth rate of new contracts between the second quarters of 2015 and 2018 (Figures A.4a and A.4b in appendix A.4 , we find there has been an expansion on the south-eastern side of the city and that the difference in units of measurement are now more pronounced, especially if we turn our focus to the north-western side of the city where the increase has been lower in absolute terms than in $€ / m^{2}$. The neighborhoods that have the highest growth rates for this period are El Parc i la Llacuna del Poblenou (58.69\%), La Barceloneta (54.38\%), Verdun $(49.79 \%)$ and La Maternitat i Sant Ramon $(41.16 \%)$ in total $€$, and in terms of $€ / m^{2}$ we find that the neighbohoods of Diagonal Mar i el Front Marítim del Poblenou (62.93\%), Verdun (48.71\%), Pedralbes (38.73\%) and El Turó de la Peira (34.93\%) have the highest growth rates. We also observe a relatively slower increase of contracts in the north-western side of the city. This part of Barcelona has been historically more expensive and we do not expect

\footnotetext{
${ }^{12}$ See Figure A.2b in Appendix A.

${ }^{13}$ We are missing data on newly signed rental contracts for a few neighborhoods, which appear filled in as blank areas.

${ }^{14}$ See figures A.3a and A.3b in appendix A.4
} 
big increases in the growth rate we are calculating. The evident discrepancy between both figures for this region may be due to a bigger size of the dwellings. As dwellings are bigger in the north-western side, the $€ / m^{2}$ changes dramatically when the price of the new contract for the whole house increases only a little bit.

Another interesting angle we can take on the data is to look at the unemployment rates for each neighborhood. The regions suffering the most in these terms are mainly located in the south-west and north-east of Barcelona (Figure A.3c in appendix A.4). The highest rates are found in La Marina del Prat Vermell - Zona Franca (14\%), La Trinitat Nova, La Trinitat Vella, Ciutat Meridiana (each with a $13 \%$ unemployment rate), Vallbona (12\%) and Canyelles (11\%). On the other hand, the lowest unemployment rates are located in Pedralbes, Vallvidrera, el Tibidabo i les Planes, Sarrià, Les Tres Torres and Sant Gervasi Galvany (each with a 3\% rate). The average unemployment rate for the sample is $8.04 \%$. We can visually compare this figure to the one of newly signed rental contracts and notice an inverse relationship: areas with lower unemployment rates have higher new contractual rents and vice versa. Looking at the growth rate of unemployment (Figure A.4c in appendix A.4.) we first find that unemployment has decreased in all areas. Like in the previous figures, neighborhoods that have always had a lower unemployment rates do not display high growth rates. However, there are some neighborhoods around the city centre that have experienced a big decline in the unemployment rate like Sant Gervasi Galvany (from 5\% to 3\%), La Dreta de L'Eixample and El Gòtic (from 6\% to $4 \%$ and from $9 \%$ to $6 \%$ respectively). We also observe that in the north-eastern side of Barcelona the unemployment rate is decreasing faster than in other areas and new rental contracts are also experiencing growth in those areas.

Lastly, we use the data on population density per neighborhood in order to see how residents from Barcelona have been allocated in the city over the last few years. We do this again by analyzing a point in time and then looking at the growth rate since 2015-Q2 (Figures A.3d and A.4d in appendix A.4). The most densely populated regions are located along the city centre from south-west to north-east, which mainly include the neighborhoods of Sants-Badal (580.5 people/Ha), Navas (522 people/Ha), Verdun (521.5 people/Ha), El Camp de l'Arpa del Clot (515 people/Ha), La Sagrada Familia (491.5 people/Ha) and El Baix Guinardó (458 people/ $\mathrm{Ha}$ ). The mean population density for the whole sample is 248.73 people/Ha, with a standard deviation of 152.21 people/Ha. Numbers on population density growth are low (average change of $1.77 \%$ with a $3.1 \%$ standard deviation), which is expected as large population displacements are not common. We can observe a slight diversion from the city centre as neighborhoods on the borders and on the beach experience an increase in population density since 2015-Q2. There is one outlier in the north of Barcelona, the 
neighborhood of La Clota with an increase in population density of $18.64 \%$. The next largest growth rate is in Torre Baró in the north-east (13.79\%) and then in La Barceloneta (9.17\%).

\section{Empirical Analysis}

\subsection{Spatial Analysis}

As reasoned in previous sections, when studying housing prices, we expect spatial dependence to emerge in our estimations. Therefore, to account for this, we include a spatial lag of the dependent variable using a spatial neighborhood matrix which reflects proximity between any two neighborhoods.

To establish the empirical relevance of our model, we construct an econometric model on the contributions of Arbia et al. (2020), Anselin (1988), Le Sage and Kelley (2009), Kapoor et al. (2007), Kelejian and Prucha (1998), Lee (2007) and Drukker and Prucha (2013). As we will show, these contributions are considered together since, due to a breach of the endogeneity assumption, we have to instrument one of the explanatory variables.

To begin with, consider the simplest first-order spatial autoregressive (SAR) model:

$$
y=\lambda W y+\varepsilon
$$

where $y$ is our dependent variable of interest, $W$ is the usual (symmetric) spatial weight matrix, $\lambda$ is a spatial autoregressive coefficient and $\varepsilon$ is an independent identically distributed error term.

Theorem 5.1 (Anselin, 1988). In the presence of spatial externalities or spillovers, the OLS will be an inconsistent estimator of our parameter of interest $(\lambda)$.

Proof: See appendix A.2

Correspondingly, if we considered a 2SLS estimation, ignoring spatial dependence in the data would lead to biased and inconsistent estimates, due to the violation of the independence assumption (LeSage and Dominguez, 2012).

Let $y$ be a column vector of observations on rents, and let $X$ be a matrix of neighborhood characteristics: row $i$ gives the characteristics of neighborhood $i$. Suppose we have a set of panel data and we believe that $y_{i}$ is influenced not only by $X_{i}$ but also by the levels of $X$ observed at $i$ 's neighbors. Besides, as we get further away from the initial change, we expect the impacts to diminish. This is the idea of general spatial effects, and it can be modelled 
by a SAR process as:

$$
\begin{aligned}
y & =\lambda W y+\beta X+\varepsilon \\
& =\left(I_{n}-\lambda W\right)^{-1} X \beta+\left(I_{n}-\lambda W\right)^{-1} \varepsilon
\end{aligned}
$$

Here, $W$ is a $(N \times N)$ spatial neighbors matrix consisting of the weights which characterize the spatial relationships between neighborhoods. Inside this matrix, the weights $w_{i j}$ denote each $(i, j)^{\text {th }}$ element belonging to $W$. So, $W_{1,2}$ specifies how much potential spillover there is from neighborhood $1\left(n_{1}\right)$ to neighborhood $2\left(n_{2}\right)$ : $W_{1,2}$ is zero if $n_{1}$ can have no effect on $n_{2}$. Obviously, the more potential spillover there is, the larger $W_{1,2}$ will be. In addition, note that $W_{i, j}=0 \forall i=j$ since neighborhood $n$ cannot be a neighbor of itself. Further, this weight matrix takes a row-standardized form: each element of $W$ is divided by the sum of all the elements in that row.

\subsubsection{Testing for spatial autocorrelation}

To test for the presence of spatial autocorrelation in the data, we perform one of the most widely used tests for spatial dependence, the Moran's (1950) test. The Moran's I test statistic is formulated in terms of a normalized quadratic form of the variables that will be tested to have spatial dependence, with the elements of a spatial-weights matrix serving as the weights in the quadratic form (Drukker and Prucha, 2013). We provide an explanation of the technicalities involved in this statistical test in appendix A.3.

We conduct the Moran's test for different years using two different spatial weight matrices: a regular contiguity matrix and a contiguity matrix containing nonzero weights for secondorder neighbors. In particular, we produce different individual and joint significance tests to see whether any of the weight matrices specify a spatial dependence. We reject almost all of the null hypotheses of no-spillovers at any conventional significance level, and we reject all of them with a $5 \%$ level of significance. That is, results obtained are a positive Moran index, which indicates positive spatial autocorrelation.

\subsection{Econometric Model}

In the econometric model, we use both rents and transaction prices as the dependent variables. We do this because, although our intention is to disentangle the effects of Airbnb on housing affordability in the rental market, our model predicts that rents and transaction prices should respond similarly to the presence of Airbnb. If the former is negatively affected, then the latter should also be negatively affected. We expect rational homeowners to update their estimate of expected stream of future income according to the actual revenue they can obtain 
in the market, which is equal to the prevailing rent prices. In this sense, we consider that the equilibrium price of a housing unit should be equal to its expected stream of future rents discounted by the appropriate internal rate of return.

Our econometric approach is based on a model with a spatial lag in the dependent variable and a spatial lag in the error structure, usually denoted as SARAR (spatial autoregressive with additional autoregressive error structure). In addition, we use a spatial panel dataset because it contains much more information and less multicollinearity among the variables than the cross-section spatial counterpart Anselin, 1988). Further, if neighborhood FEs exist, a cross-section estimator will be consistent only as long as this individual effect can be assumed to be uncorrelated with the other explanatory variables. Otherwise, a consistent treatment of these correlated effects can only be based on data having a time-series dimension. Therefore, the model takes the following form:

$$
\begin{aligned}
y_{i t} & =\lambda W y_{i t}+\beta X_{i t}+\eta_{i}+\varepsilon_{i t} \\
\varepsilon_{i t} & =\rho W \varepsilon_{i t}+v_{i t}
\end{aligned}
$$

In order to bring our theoretical findings into data, we base the model on definitions (6), (7) and (9). We proxy an econometric setting with different variables that bring us the most suitable available information. So, we take the function

$$
y_{n t}=\lambda W y_{n t}+\beta A i r b n b_{n t}+X_{n t}{ }^{\prime} \theta+\eta_{n}+\tau_{t}+\varepsilon_{n t}
$$

where $y_{n t}$ is the log of our measure of housing rents or prices in neighborhood $n$ at time $t$, $A_{i r b n b_{n t}}$ is the number of active listings in neighborhood $n$ at time $t, X_{n t}$ is a column vector of time-varying controls, $\eta_{n}$ are neighborhood FEs that account for time-invariant neighborhood characteristics ${ }^{15} \tau_{t}$ are time dummies ${ }^{16}$ and $\varepsilon_{n t}$ is the error-term of the regression model, which is modelled as in $12 \mathrm{~b}$. For $W$, we follow the general procedure and scale the weight matrix so that its largest eigenvalue is equal to 1 . We make use of the so-called spatial contiguity matrix (Anselin, 1988) containing nonzero weights for second-order neighbors. We do this because we consider that there are spillover effects from adjacent areas and even from areas next door to adjacent areas. We consider using the contiguous form to be the most appropriate choice. Suppose we have three neighborhoods in a line: A-B-C, so that A is a neighbor of $\mathrm{B}, \mathrm{B}$ is a neighbor of $\mathrm{A}$ and $\mathrm{C}$; and $\mathrm{C}$ is a neighbor of $\mathrm{B}$ (but not $\mathrm{A}$ ). Suppose

\footnotetext{
${ }^{15}$ These neighborhood-specific effect $\eta_{n}$ captures the existence of other determinants of a neighborhood's state that are not already accounted by the other regressors.

${ }^{16}$ These time dummies may be expected to capture global shocks affecting housing rents and/or prices across Barcelona.
} 
there exists a positive spatial autocorrelation in prices. If prices rise in A, what will happen in $\mathrm{C}$ ? If we use a standard contiguity matrix, $\mathrm{A}$ and $\mathrm{C}$ will not be neighbors. Therefore, there will be no first-order indirect effect from A to C. However, A influences B: the increase of prices in $\mathrm{A}$ causes a rise of prices in $\mathrm{B}$. As a consequence, the price in $\mathrm{C}$ will also rise. Thus, the effect on $\mathrm{C}$ will be a second-order (smaller) indirect effect: the price in $\mathrm{C}$ will rise because prices will have increased in its neighboring region, B. In the same way, if we had five neighborhoods X-A-B-C-D including nonzero weights for second-order neighbors would imply that $\mathrm{A}$ affects $\mathrm{C}$ through a first-order indirect effect, but not $\mathrm{D}$. Instead, D would be affected just through a second-order indirect effect, just in the same way as $\mathrm{C}$ was affected in the previous example. Likewise, in our particular case, we consider that the amount spilled over from second-order neighbors is half as that from first-order neighbors. So, we define $W_{s, n}$ for second-order neighbors as half of that for first-order neighbors.

As for $X_{n t}$, we include the following set of time-varying control variables: the average surface of the rented dwellings $\left(m^{2}\right.$ built) 17 the weight of registered unemployment of the population aged 16 to 64 and log of population. ${ }^{18}$ We do not include controls for average age, relative income and percentage of foreign residents because these data are not available at the quarterly level.

As outlined by Barron et al. (2018) and Garcia-López et al. (2019), there may still be some unobserved neighborhood-specific, time-varying factors contained in the error term that are correlated with Airbnb $_{n t}$, even after including appropriate controls and FEs into the model. For this reason we include an instrumental variable which is almost identical to the ones proposed by these authors.

\subsection{Instrumental variable}

In order to address potential endogeneity of the independent variable $A_{i r b n b_{n t}}$, we need to use an instrumental variable. This variable needs to be correlated with Airbnb $b_{n t}$ at the neighborhood level and has to be exogenous to neighborhood level shocks to the long-term rent in the housing market (Barron et al., 2018). Considering this, we construct a Bartiklike instrument. Goldsmith-Pinkham et al. (2018) define a Bartik-like instrument as an instrument that uses the inner product structure of the endogenous variable, Airbnb $b_{n t}$ in our case.

\footnotetext{
${ }^{17}$ These date are obtained by crossing the information of the dwellings registered in the Cadastre with the rental contracts that have deposited a rental agreement deposit in Incasòl. This information could be gathered for about $90 \%$ of the new agreed contracts.

${ }^{18}$ The data presented in this data-set for unemployment correspond to an estimate of Barcelona's registered unemployment at the neighborhood level, based on the data provided by the Department of Labor, Social Affairs and Families (Government of Catalonia) by postal code.
} 
For the shift component of the instrumental variable, we follow Barron et al. (2018) and we use the worldwide searches in Google for the term "Airbnb Barcelona" for the years 2015 to 2018, at the quarterly level. This variable is a measure of the popularity of a search in the geographic and time range specified and it is normalized to 100 for the period with the highest number of searches. Thus, values of this variable express how popular the search was compared to the most popular quarter of the entire time range. This part of the instrument is used to measure the popularity of Airbnb in Barcelona and hence, when Airbnb listings will most likely appear.

The share component of the instrument will predict where Airbnb listings will appear. To that aim, we follow the strategy of Garcia-López et al. (2019) and we construct an index that measures proximity to tourist amenities, which will be used as a measure of how attractive a given neighborhood is for tourists. A list of touristic amenities in Barcelona is obtained from TripAdvisor's site and they are weighted by their relative importance, given by their number of reviews in Google. Then, the measure is constructed as follows:

$$
\text { TouristAmenities }_{n}=\sum_{k} \frac{1}{\text { dist }_{n, k}} \times \text { Reviews }_{k}
$$

where $k$ indicates the amenity, dist $_{n, k}$ the distance in meters from the centroid of each neighborhood $n$ to the amenity $k^{19}$ and Reviews $s_{k}$ is the number of Google reviews of the amenity $k$.

The rationale behind this is that tourists' willingness to pay is higher the closer to the amenities. This will result in a higher proportion of Airbnb listings and also in higher prices. Hence, the assumption is that homeowners in more touristic neighborhoods are more likely to switch from the long-term market to the short-term market because they expect their dwellings to be rented more frequently and at higher prices.

\subsubsection{Validity of the instrument}

Goldsmith-Pinkham et al. (2018) show that the identifying assumption for the share-shift instrument relies on the share component, and variation in the shift component only contributes to instrument relevance. To support evidence of the relevance of the instrument, Garcia-López et al. (2019) show how the variation in Google Trend searches closely tracked the time variation of Airbnb activity, suggesting that the shift component does contribute to the relevance of the instrument.

On the other hand, Figure 5 a shows Airbnb listings as a function of the log of tourist amenities index, indicating a positive relationship between the share component of the instru-

\footnotetext{
${ }^{19}$ For this distance we established a minimum of 250 meters.
} 
ment and Airbnb activity. This means that neighborhoods that are closer to tourist amenities tend to have a higher amount of Airbnb listings. In Figure $5 \mathrm{~b}$ we plot Airbnb listings as a function of the instrumental variable, $z_{n t} \equiv \ln \left(\right.$ TouristAmenities $_{n} \times$ GoogleTrend $\left._{t}\right)$. We observe a positive correlation between the number of Airbnb listings and the instrument, which supports the relevance of the instrument.

In Figure A.5, in the appendix A.4, we also provide a comparison of the mean value of the instrument and the average number of Airbnb listings over the period studied.

Figure 5: Prediction capacity of the IV

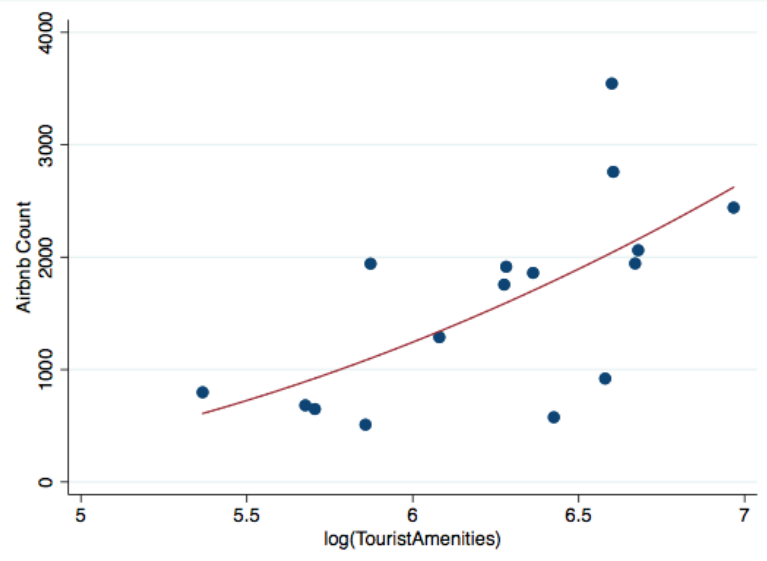

(a) Airbnb activity and tourist amenities

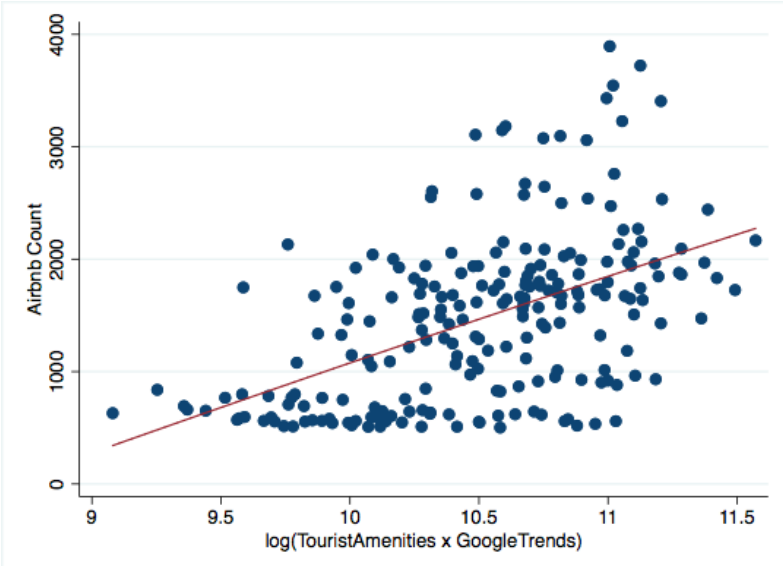

(b) Airbnb activity and the shift-share IV

Notes: The sample is restricted to observations where we can find more than 500 Airbnb listings. For a), we randomly picked the 2017-Q1 period to test the cross-sectional part of the IV.

First-stage coefficients are reported in Table 1. These coefficients result from regressing $\operatorname{Airbnb}_{n t}$ on $z_{n t}$. It can be seen that coefficients are positive and significant, meaning that there is clearly a positive relationship between the two variables, as stated above. Table 1 also shows Effective F statistics of 31.075 and 55.11, respectively. These are resulting from performing the Olea-Pflueger robust weak-instrument test (Olea and Pflueger, 2013), which allows for errors that are not conditionally homoskedastic and serially uncorrelated. Hence, we can reject that the estimator's approximate asymptotic bias exceeds a fraction 10-5\% of a "worst-case" situation when instruments are completely uninformative and when first-stage and second-stage errors are perfectly correlated.

After removing neighborhood-specific characteristics by using a fixed-effects specification, the exogeneity of the instrument relies on the assumption that changes in housing rents are only correlated with the distance to tourist amenities through Airbnb $_{n t}$. We believe that this is a plausible assumption, since there is no reason to believe that preferences of residents regarding proximity to tourist amenities have changed over our three years period of study. To ensure the plausibility of this assumption, Garcia-López et al. (2019) study if proximity to 
Table 1: First stage: shift-share IV

\begin{tabular}{|c|c|c|}
\hline \multirow[b]{3}{*}{ Variable } & \multicolumn{2}{|c|}{ Airbnb Count } \\
\hline & (i) & (ii) \\
\hline & OLS & OLS \\
\hline $\ln \left(\right.$ TouristAmenities $_{n}$ & $3.51^{* * *}$ & $8.66^{* * *}$ \\
\hline$\times$ GoogleTrends $\left.s_{t}\right)(/ 100)$ & $(0.934)$ & $(1.68)$ \\
\hline Observations & 1,005 & 1,005 \\
\hline Neighborhood FE & Yes & Yes \\
\hline Time FE & Yes & Yes \\
\hline Quarter FE & No & Yes \\
\hline Effective $F^{E}$-statistic & 31.08 & 55.11 \\
\hline
\end{tabular}

Notes: Reported standard errors are clustered at the neighborhood.

level. ${ }^{* * *} p<0.01,{ }^{* *} p<0.05,{ }^{*} p<0.1$.

tourist amenities explained changes in housing rents and prices before the arrival of Airbnb and they find evidence that pretrends in terms of rents were not statistically different between neighborhoods closer and further away from tourist amenities. This finding supports the exogeneity of the instrument.

\subsection{Implementation of the model}

To implement our instrumental variable, we consider the generalized spatial two-stage least squares (GS2SLS) estimator derived by Kelejian and Prucha (1998). These same authors propose a generalized method of moments (GMM) estimation which can be found in Kelejian and Prucha (2001a).

To obtain the $(x, y)$ coordinates of places, we use a shapefile provided by the Cartographic Coordination Commission of Catalonia which contains the latitude and longitude coordinates that build the map of the city of Barcelona. Then, to proceed with the estimation, we adapt our data in Stata to be spatial and create our weight matrix $W$. Once the data is properly set up, we switch to Matlab and use the Toolbox developed by Alvarez et al. (2017). When the model contains a spatial lag of the error structure, this toolbox implements the GMM estimations proposed by Kapoor et al. (2007), Mutl and Pfaffermayr (2011) or Piras (2013). 
Specifically, we implement a fixed-effects spatial two-stage least squares (FES2SLS) allowing for endogeneity in Airbnb $b_{n t}$. We instrument Airbnb $b_{n t}$ with $z_{n t}$, and set a spatial lag of the dependent variable and the error structure. To check for the consistency of the FE estimator, we conduct the Hausman test (Hausman, 1978) that compares the GLS estimator of the random effects (RE) model and the within estimator in the FE model. In our case, we apply the spatial Hausman test described in Mutl and Pfaffermayr (2011). We reject the null hypothesis that the RE (GLS) estimator is more efficient than the FE estimator at any conventional level of significance.

\section{Empirical Results}

Table 2 depicts the main results obtained when running different regression models. ${ }^{20}$ All the columns in Table 2 refer to some specification of equation (13) after controlling for seasonality through the inclusion of dummies for each quarter. Columns (i) and (ii) show the results from regressions of an incomplete specification of equation (13), not taking into account spatial dependence. Lastly, column (iii) refers to the full specification in (13), allowing for spatial dependence in both rents and prices.

At first, when we consider rents, $A i r b n b_{n t}$ has a significant positive effect in the two incomplete specifications (i) and (ii). Specifically, equation (i) shows that (on average) a 100unit increase in $A_{i r b n b}$ induces a 7.8 percent increase in long-term rental rates. Yet, when we control for year FEs, the Airbnb effect decreases to 2.1 percent. Similarly, when a spatial regression model is used, i.e. equation (iii), this beta coefficient decreases to 1.7 percent for a 100-unit increase in $A_{i r b n b_{n t}}$. All of these effects are significant at any conventional level of significance in both (i) and (ii). With regard to transaction prices, we only get significant coefficients for $A_{i r b n b_{n t}}$ if we do not control for year FEs nor spatial spillovers. In such case, we get that a 100-unit increase in Airbnb listings causes a 5.1\% increase in housing prices.

Notice, however, that as explained in e.g. LeSage and Dominguez (2012), we cannot draw conclusions based on the coefficients $\beta$ from a spatial regression model. In fact, 2SLS estimates from columns (i) and (ii) and FES2SLS estimates from column (iii) in Table 2 are not directly comparable. However, it is not our intention to make this comparison, but rather to highlight that independent regression models are simply inappropriate for use in situations involving intuitively or theoretically obvious dependence, leading to incorrect conclusions.

In order to draw meaningful conclusions about the total effect of Airbnb on long-term rents and prices, both direct and indirect effects need to be calculated. This is exactly what we do in section 6.1.

\footnotetext{
${ }^{20}$ Complete regression estimates can be found in appendix A.4. Table 4
} 
Table 2: Main regression results

\begin{tabular}{|c|c|c|c|c|c|c|}
\hline \multirow[b]{3}{*}{ Variable } & \multicolumn{3}{|c|}{ Rents, $\ln \left(€ / m^{2}\right)$} & \multicolumn{3}{|c|}{ Prices, $\ln \left(€ / m^{2}\right)$} \\
\hline & (i) & (ii) & (iii) & (i) & (ii) & (iii) \\
\hline & 2SLS & 2SLS & FES2SLS & 2SLS & 2SLS & FES2SLS \\
\hline \multirow[t]{2}{*}{ Airbnb count $(x 100)$} & $0.078^{* * *}$ & $0.021^{* * *}$ & $0.017^{* * *}$ & $0.051^{*}$ & -0.013 & -0.004 \\
\hline & $(0.023)$ & $(0.006)$ & $(0.006)$ & $(0.029)$ & $(0.019)$ & $(0.014)$ \\
\hline \multirow[t]{2}{*}{$\mathrm{W} \cdot \ln (\mathrm{y})$} & \multirow{2}{*}{ - } & \multirow[b]{2}{*}{-} & 0.205 & \multirow{2}{*}{-} & \multirow{2}{*}{-} & $0.638^{* * *}$ \\
\hline & & & $(0.169)$ & & & $(0.230)$ \\
\hline Observations & 1,005 & 1,005 & 1,005 & 975 & 975 & 975 \\
\hline Neighborhood FE & Yes & Yes & Yes & Yes & Yes & Yes \\
\hline Quarter FE & Yes & Yes & Yes & Yes & Yes & Yes \\
\hline Year FE & No & Yes & Yes & No & Yes & Yes \\
\hline Spatial spillovers & No & No & Yes & No & No & Yes \\
\hline
\end{tabular}

Notes: For 2SLS models, reported standard errors are clustered at the neighborhood level.

For FES2SLS models, we include spatial lags of the dependent variable and the error structure.

*** $p<0.01,{ }^{* *} p<0.05,{ }^{*} p<0.1$.

\subsection{Impact Measures}

Due to the possible presence of spatial transmission mechanisms (externalities and spillovers), spatial models require a particular interpretation of the parameters. In particular, spatial regression models expand the information set to include information from neighboring observations (Anselin, 1988). To facilitate the interpretation of marginal effects, impact measures ${ }^{21}$ have been suggested in the literature [see Le Sage and Kelley (2009)].

Recall that when Airbnb $b_{n t}$ increases, this impacts $y_{n t}$, and that effect in $y_{n t}$ spills over and produces a further reaction in $y_{n t}$. This latter indirect effect spills over again to produce yet another effect on $y_{n t}$, and so on. The role of impact measures is, precisely, to illustrate the average effects from this recursive process. For this reason, we report our impact measures of interest, for both rents and transaction prices, in Table $3{ }^{22}$ To test the significance of these

\footnotetext{
${ }^{21}$ Average Direct Impacts (ADI), Average Indirect Impacts (AII) and Average Total Impacts (ATI).

${ }^{22}$ Complete impact estimates can be found in appendix A.4. Table 5
} 
impact measures, we follow the classical delta method, as suggested by Arbia et al. (2020). ${ }^{23}$

Table 3: Main impact measures

\begin{tabular}{|c|c|c|c|c|c|c|}
\hline & \multicolumn{3}{|c|}{ Rents, $\ln \left(€ / m^{2}\right)$} & \multicolumn{3}{|c|}{ Prices, $\ln \left(€ / m^{2}\right)$} \\
\hline & ADI & AII & ATI & ADI & AII & ATI \\
\hline \multirow[t]{2}{*}{ Airbnb count (x100) } & $0.0166^{* * *}$ & 0.0042 & $0.0208^{* * *}$ & -0.0037 & -0.0062 & -0.0098 \\
\hline & $(0.0060)$ & $(0.0038)$ & $(0.0064)$ & $(0.0147)$ & $(0.0240)$ & $(0.0385)$ \\
\hline
\end{tabular}

Notes: Reported standard errors are based on the classical delta method. ADI, AII and ATI stand for Average Direct Impact, Average Total Impact and Average Total Impact, respectively.

*** $p<0.01,{ }^{* *} p<0.05,{ }^{*} p<0.1$.

In Table 3, we report average percentage changes in rents and prices for a one-unit increase in the number of Airbnb listings. The direct effect (ADI) corresponds to the impact induced by a one-unit increase of $A_{i r b n b_{n t}}$ in $y_{n t}$ within a given neighborhood, ignoring spillover effects. This own-neighborhood direct effect is to increase housing rents by $1.7 \%$ for every 100-units increase in Airbnb ${ }_{n t}$. In contrast, the indirect effect (AII) is the spillover effect. An increase in the presence of Airbnb increases rents, and this increase spills over to further raise rents. The result (namely, the total effect) is a 2.1 percent increase in rents, which is simply the sum of the direct and indirect effects. Note that this coefficient is significant at any conventional level of significance.

Finally, as a robustness check, we also estimate the standard errors using the Pierce method, getting very similar results.

\subsection{Interpretation of the results}

Our analysis delivers an interesting finding: when allowing for spatial spillovers, we conclude that an increase in the number of Airbnb triggers an increase in long-term rental rates, obtaining estimates which are in line with other authors such as Garcia-López et al. (2019) suggest. Hence, we provide empirical evidence which further supports the idea that Airbnb contributes to increase housing rents.

Nevertheless, the novelty of this study is to get these results by means of an appropriate econometric specification that allows for spatial dependence in the data, and thus is unbiased and consistent. The role of spatial dependence can be clearly seen in both tables 2 and 3 . In

\footnotetext{
${ }^{23}$ In a Monte Carlo simulation, they show that the delta method outperforms the estimating equation approach (Pierce) and the simulation method when it comes to estimating the AII and ATI measures.
} 
Table 2, we can observe that (in a given neighborhood) allowing for spatial spillovers in our specification reduces the direct effect of a 100-units increase of $A_{i r b n b_{n t}}$ on rents from 2.1 to 1.7 percent. Similarly, in Table 3, we can see that taking into account indirect effects leads to a total effect of 2.08 percent. One may argue that, however, (at the end) we get to the same total estimated impact. Nonetheless, this is just a coincidence and may not hold when using another sample data.

As for prices, there seems to exist no "Airbnb effect", which contradicts our predictions from Section 3. The simplest explanation would question the rationality of homeowners, and the way in which they discount the value of the future stream of income they receive; or simply that prices take longer to adjust than rents, and so results do not yet emerge in our data. On the contrary, we consider that a more plausible explanation is that owners do not really believe that home-sharing platforms are sustainable in the long-run, and hence do not expect much future cash flows emerging from their use in the longer term. This possibility leaves room for future research in which more detailed models are developed.

\section{Conclusions}

In this paper, we set out to study the effect of the sharing economy on the housing market. Specifically, we quantify to what extent Airbnb is responsible for the increase in both contractual rental rates and transaction purchasing prices in the city of Barcelona from 2015-Q2 to 2018-Q4. We construct a novel theoretical model allowing for spatial dependence and inter-neighborhood spillovers and implement a fixed-effects spatial 2SLS method allowing for endogeneity in the variable which measures the presence of Airbnb.

The theoretical model predicts that a change in the level of Airbnb activity might affect both long-term rents and housing prices. In addition, the model bears upon the effects of Airbnb on gentrification and displacement: an increase in negative externalities will lead to a reduction in the local demand for long-term housing. As a result, rents will suffer a downward pressure, increasing the profitability on the short-term rental market for homeowners. This effect will be aggravated if there is spatial dependence. Local residents will be inclined to move to other neighborhoods in which not only the presence of Airbnb is lower, but also where the penetration of Airbnb is small enough in the adjacent neighborhoods. We refer to this process as Airbnb-induced gentrification. Likewise, if the profitability of renting a property on Airbnb increases, a similar process as the one we have just described above would arise, which would also lead to gentrification.

Furthermore, our main empirical results show that Airbnb positively and significantly affects rents, even when accounting for spatial dependence and inter-neighborhood spillovers. 
In a given neighborhood (as classified in this paper), for every additional 100 Airbnb listings, rents increase by an average of 2.08 percent when indirect spillovers coming from adjacent neighborhoods are included. In particular, the direct effect of Airbnb within a given neighborhood accounts for much of this effect: the own-neighborhood effect is to induce a $1.7 \%$ increase in rents. The maximum average indirect effect found in the sample data accounts for $35 \%$ of the total effect ${ }^{24}$ The implications of these findings are far reaching and suggest that spillover effects can indeed explain a large portion of rent increases. Likewise, we identify a potential bias in the previous literature in that the total effect is falsely interpreted as the direct effect, thereby misinterpreting the direct effect of Airbnb on long-term rents.

In contrast, our empirical results show that Airbnb has had no significant effect on transaction prices. The most plausible explanation for the non-significant results for prices is that homeowners do not believe that Airbnb is actually sustainable in the long-run, and therefore they do not adjust their predicted future cash flows when valuing their properties.

Finally, we believe that future research could delve into more detailed theoretical models, especially with respect to the price setting by homeowners in light of the establishment of Airbnb. Additionally, we think that making a distinction between direct and indirect neighborhood effects is vital in order to truly understand the dynamics of the housing markets, especially in the growing metropoles. Accordingly, we encourage scholars to further apply and develop spatial econometric methods that measure indirect spillover effects in studies related to housing markets.

\footnotetext{
${ }^{24}$ This $35 \%$ is the ratio of the upper bounds of the confidence intervals of AII and ATI.
} 


\section{A Appendix}

\section{A.1 Derivations for the Model}

\section{Deriving $\mathrm{c}_{\mathrm{j}}^{*}$ :}

Take the utility function

$$
U_{i, n}=Y_{i}-R_{n}+a_{i, n}-\alpha\left[F_{c}\left(c_{j, n}^{*}\right)+\gamma \sum_{s \neq n} \omega_{s, n} F_{c}\left(c_{j, s}^{*}\right)\right]
$$

Suppose the market is in equilibrium:

$$
T_{n}-c_{j, n}^{*}=R_{n}
$$

Normalize the marginal resident's utility such that $U_{i, n}=Y_{i}$ :

$$
R_{n}\left(a_{i, n}^{*}\right)=a_{i, n}^{*}-\alpha\left[F_{c}\left(c_{j, n}^{*}\right)+\gamma \sum_{s \neq n} \omega_{s, n} F_{c}\left(c_{j, s}^{*}\right)\right]
$$

As implied by equilibrium,

$$
S_{n}\left[1-F_{c}\left(c_{j, n}^{*}\right)\right]=1-F_{a}\left(a_{i, n}^{*}\right)
$$

Assume $c_{j}$ and $a_{i}$ are $U \sim(0,1)$. This implies that

$$
\begin{gathered}
a_{i, n}^{*}=R_{n}+\alpha\left[c_{j, n}^{*}+\gamma \sum_{s \neq n} \omega_{s, n} c_{j, s}^{*}\right] \\
\Rightarrow S_{n}\left(1-c_{j, n}^{*}\right)=1-T_{n}+c_{j, n}^{*}-\alpha\left[c_{j, n}^{*}+\gamma \sum_{s \neq n} \omega_{s, n} c_{j, s}^{*}\right]
\end{gathered}
$$

Assume also that $c_{j, n}^{*}=c_{j, s}^{*}=c^{*} \forall n \neq s$. Then,

$$
\begin{aligned}
S_{n}\left(1-c_{j}^{*}\right)=1-T_{n}+c_{j}^{*}-\alpha c_{j}^{*}-\alpha \gamma c_{j}^{*} \\
\Rightarrow S_{n}-1+T_{n}=S_{n} c_{j}^{*}+c_{j}^{*}-\alpha c_{j}^{*}-\alpha \gamma c_{j}^{*} \\
=c_{j}^{*}\left[S_{n}+1-\alpha(1+\gamma)\right]
\end{aligned}
$$

Therefore,

$$
c_{j}^{*}=\frac{S_{n}-1+T_{n}}{S_{n}+1-\alpha(1+\gamma)}
$$


For $T_{n}=A_{n}+\phi \sum_{s \neq n} \omega_{s, n} T_{s}$ it can be seen that

$$
c_{j}^{*}=\frac{S_{n}-1+A_{n}+\phi \sum_{s \neq n} \omega_{s, n} T_{s}}{S_{n}+1-\alpha(1+\gamma)}
$$

If we assume that $T_{n}=T_{s}=T^{*} \forall n \neq s$, then 23 can be simplified to:

$$
c_{j}^{*}=\frac{S_{n}-1+A_{n} /(1-\phi)}{S_{n}+1-\alpha(1+\gamma)}
$$

\section{Deriving $\mathbf{R}_{\mathbf{n}}$ :}

Suppose (again) the market is in equilibrium and plug equation (19) into (18), where $c_{j}$ and $a_{i}$ are $U \sim(0,1)$ and $c_{j, n}^{*}=c_{j, s}^{*}=c^{*} \forall n \neq s$ :

$$
\begin{aligned}
& S_{n}\left(1-c_{j}^{*}\right)=1-R_{n}-\alpha\left(c_{j}^{*}+\gamma c_{j}^{*}\right) \\
\Rightarrow & R_{n}=\left[S_{n}-\alpha(1+\gamma)\right] c_{j}^{*}(\phi)-\left(S_{n}-1\right)
\end{aligned}
$$

\section{Deriving $\mathbf{P}^{*}$ :}

Take the following expression:

$$
\begin{aligned}
P_{n} & =\sum_{t=0}^{\infty} \delta^{t}\left[\left(1-c_{j}^{*}\right) R_{n}+\int_{0}^{c_{j}^{*}}\left(T_{n}-c\right) d c\right] \\
& =\frac{1}{1-\delta}\left[R_{n}+\left(T_{n}-R_{n}\right) c_{j}^{*}-\frac{\left(c_{j}^{*}\right)^{2}}{2}\right]
\end{aligned}
$$

Then, if $T_{n}=T_{s}=T^{*}$ and $R_{n}=R_{s}=R^{*} \forall n \neq s$, we will have that

$$
P_{n}=P^{*}=\frac{1}{1-\delta}\left[R^{*}+\frac{\left(c_{j}^{*}\right)^{2}}{2}\right] \quad \text { for all } n \in\{1, \ldots, N\}
$$

\section{A.2 Omitted Proofs}

\section{Proof of Proposition 3.1:}

By the definition of an economic equilibrium and continuous variables, we must have a point in which $T_{n}-R_{n}=c_{j}$. Suppose $T_{n}-R_{n}>c_{j}$ for some $T_{n}, R_{n} \in \mathbb{R}^{+}$. Then, there must exist another cost level $x \in \mathbb{R}^{+}$sufficiently close to $c_{j}$ with both $T_{n}-R_{n} \geq x$ and $x>c_{j}$ 


\section{Proof of Theorem 5.1:}

We proceed as in Anselin (1988): The OLS estimate of $\lambda$ is $\hat{\lambda}=\left(y^{\prime} W^{\prime} W y\right)^{-1} y^{\prime} W^{\prime} y$, which implies that $\hat{\lambda}-\lambda=\left(y^{\prime} W W y\right)^{-1} y^{\prime} W \varepsilon$. Therefore, if $p \lim _{N \rightarrow \infty} N^{-1}\left(y^{\prime} W^{\prime} W y\right)=Q$ is a finite and non-singular matrix, it is straightforward to show that the consistency of the OLS estimator will depend on the condition $p \lim _{N \rightarrow \infty} N^{-1} y^{\prime} W \varepsilon=0$, which will not hold in our spatial case unless $\lambda=0$, since the presence of the spatial weight matrix results in a quadratic form in the error terms:

$$
p \lim _{N \rightarrow \infty} \frac{1}{N} y^{\prime} W \varepsilon=p \lim _{N \rightarrow \infty} \frac{1}{N} \varepsilon^{\prime} W(I-\lambda W)^{-1} \varepsilon
$$

\section{A.3 Statistical Tests}

\section{The Moran's Test:}

Consider the following model:

$$
y=X \beta+u
$$

where $y$ is a $n \times 1$ dependent-variable vector, $X$ is a $n \times K$ matrix of covariates, $\beta$ is a $K \times 1$ vector of regression parameters, and $u$ is a $n \times 1$ vector of disturbances. We assume that $u_{i}$ are identically distributed with $\mathbb{E}\left(u_{i}\right)=0$ and $\mathbb{E}\left(u_{i}^{2}\right)=\sigma^{2}$, and we want to test the hypothesis that the $u_{i}$ are also uncorrelated; i.e. we want to test

$$
H_{0}: \mathbb{E}\left(u u^{\prime}\right)=\sigma^{2} I_{n}
$$

As explained in Drukker and Prucha (2013), we first consider the case where we believe that $W_{1}$ provides a proper representation of potential links for spatial inter-dependencies between the $u_{i}$. In this case, we could test $H_{0}$ using the standard Moran $I$-test statistic:

$$
I_{n}=\frac{\hat{u}^{\prime} W \hat{u}}{\hat{\sigma}^{2}\left[\operatorname{tr}\left\{\left(W^{\prime}+W\right) W\right\}\right]^{1 / 2}}
$$

based on $W=W_{1}$, where $\hat{u}=y-X \hat{\beta}$ denotes the OLS residuals and $\hat{\sigma}^{2}=n^{-1} \hat{u}^{\prime} \hat{u}$ is the corresponding estimator for $\sigma^{2}$. Under appropiate assumptions, it would follow that $I \sim N(0,1)$, and thus we would have a proper definition for our $I$-test statistic.

Next, we consider a different case where we are not sure whether any of the weight matrices $\mathrm{W}_{1}, \mathrm{~W}_{2}, \ldots, \mathrm{W}_{g}$ properly model the spatial inter-dependence between the $u_{i}$. In this case, we 
could test $H_{0}$ using the following $I(q)^{2}$ test-statistic:

$$
I(q)^{2}=\left[\begin{array}{c}
\hat{u}^{\prime} W_{1} \hat{u} / \hat{\sigma}^{2} \\
\vdots \\
\hat{u}^{\prime} W_{q} \hat{u} / \hat{\sigma}^{2}
\end{array}\right]^{\prime} \Phi^{-1}\left[\begin{array}{c}
\hat{u}^{\prime} W_{1} \hat{u} / \hat{\sigma}^{2} \\
\vdots \\
\hat{u}^{\prime} W_{q} \hat{u} / \hat{\sigma}^{2}
\end{array}\right]
$$

where $\Phi=\left(\phi_{r s}\right)$ and $r, s=1, \ldots, q$ :

$$
\phi_{r s}=\frac{1}{2} \operatorname{tr}\left\{\left(W_{r}+W_{r}^{\prime}\right)\left(W_{s}+W_{s}^{\prime}\right)\right\}
$$

From Kelejian and Prucha (2001b) and Drukker and Prucha (2013), it would follow that $I(q)^{2} \sim \chi^{2}(q)$ under the null hypothesis $H_{0}$.

\section{A.4 Figures}

Figure A.1: Long-term rents and Airbnb listings

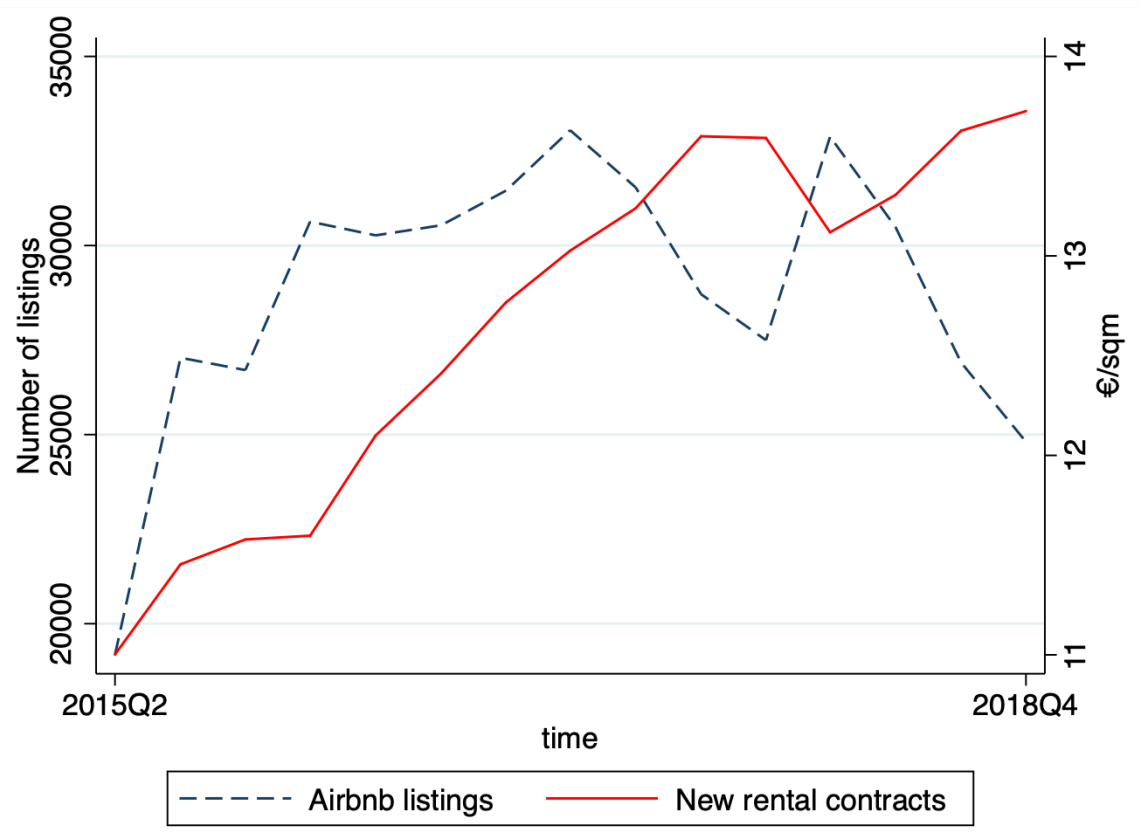


Figure A.2: Airbnb density in 2018-Q2 and its evolution since 2015-Q2

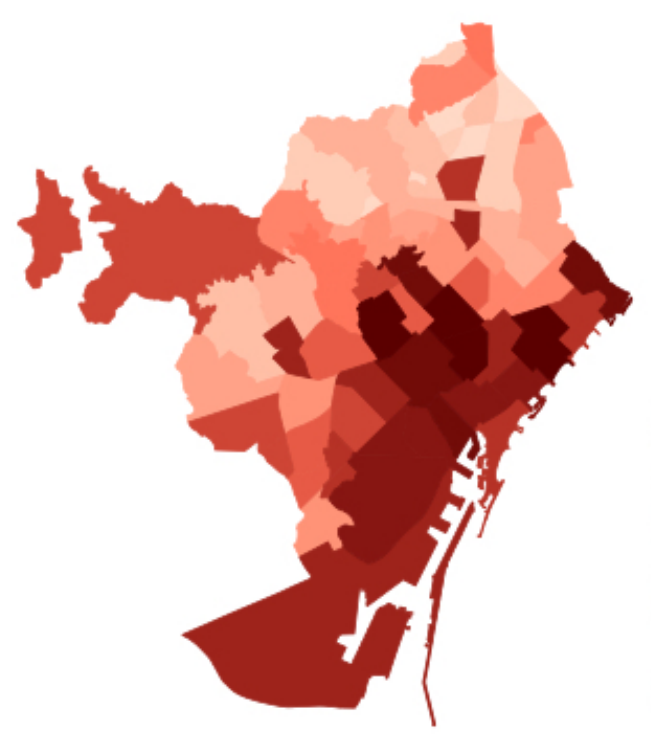

(a) Airbnb density

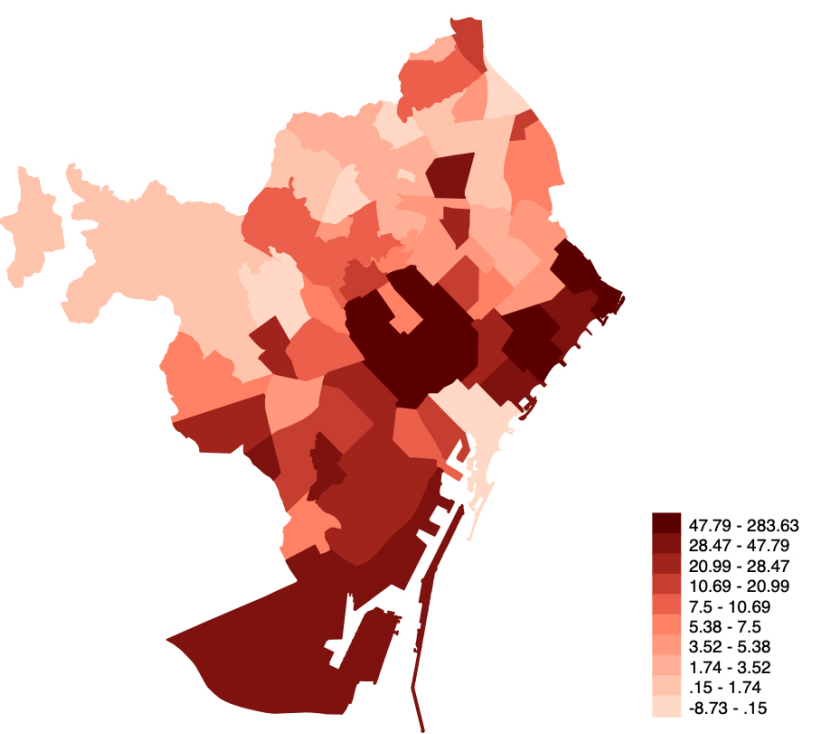

(b) Evolution of Airbnb density 
Figure A.3: Values of descriptive statistics data (2018-Q2)
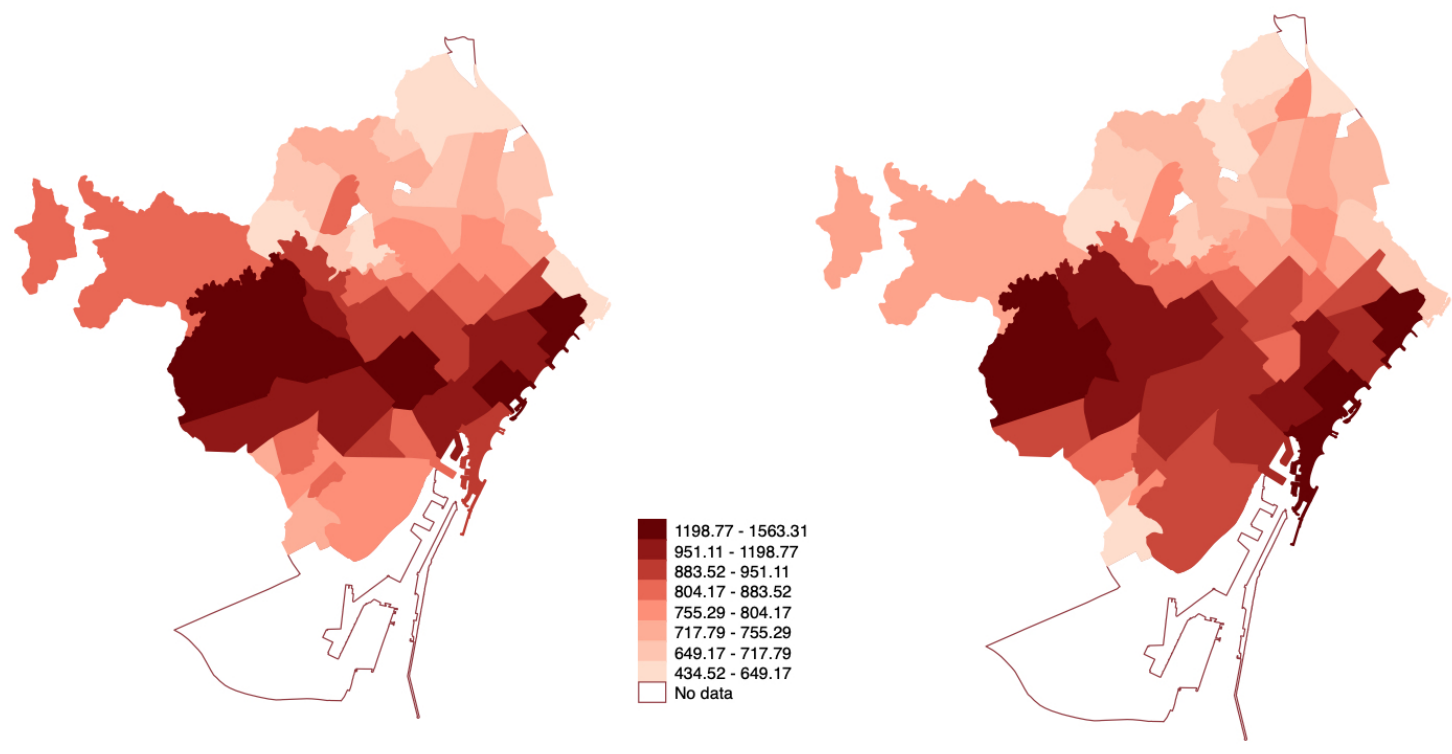

$15.83-18.15$

$13.42-14.27$

$13.04-13.42$

$12.62-13.04$

$11.89-12.62$

$11.55-11.89$

$11.12-11.55$ $10.24-11.12$ $7.22-10.24$ No data

(a) New rental contracts in $€$

(b) New rental contracts in $€ / m^{2}$

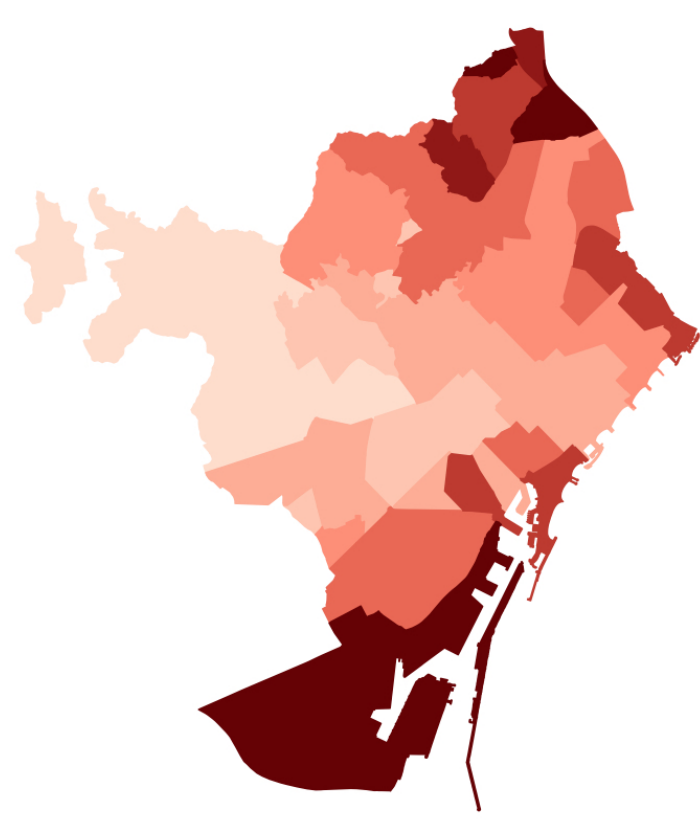

(c) Unemployment rate

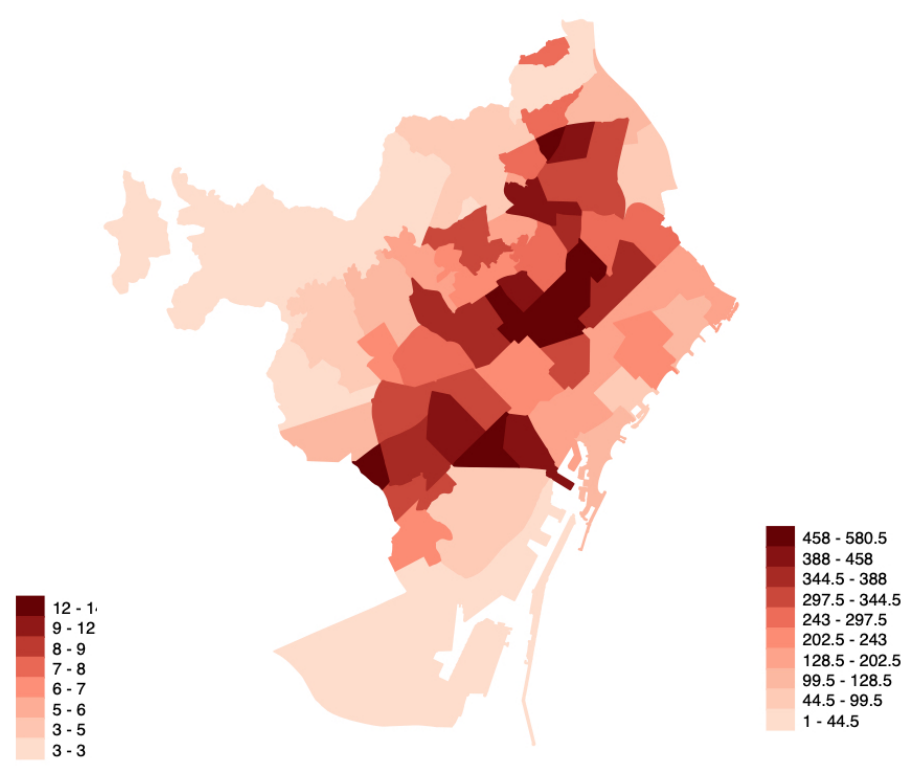

(d) Population density 
Figure A.4: Growth rate of descriptive statistics data in 2018-Q2 relative to 2015-Q2
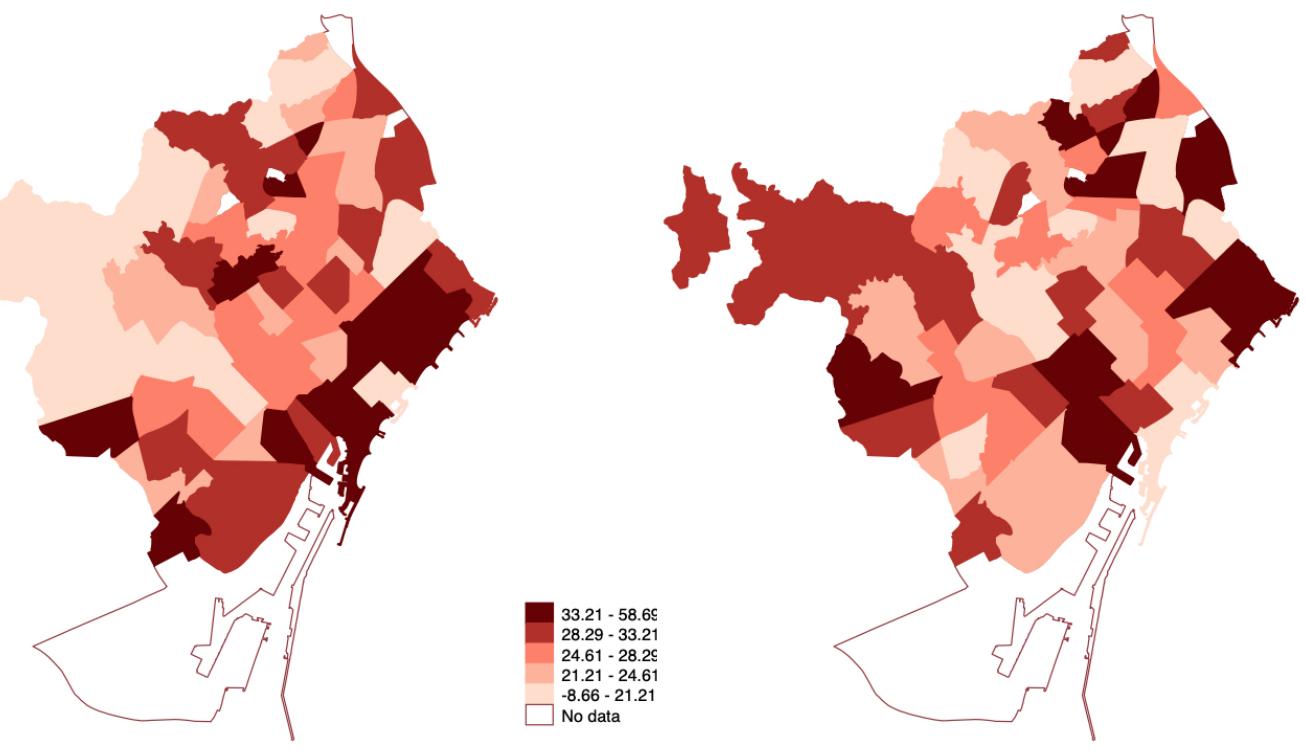

$27.13-62.93$
$23.48-27.13$

$20.42-23.48$ $16.36-20.42$
$-1.23-16.36$ No data

(a) Growth rate of new rental contracts in $€$

(b) Growth rate of new rental contracts in $€ / m^{2}$

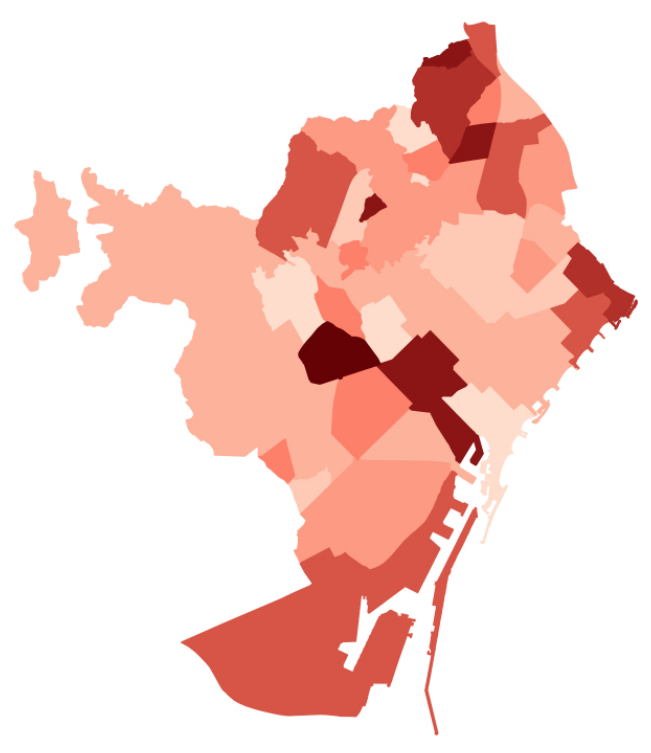

$-33.33--40$
$-30.77--33.3$
$-30--30.77$
$-28.57--30$
$-27.27--28.5$
$-25--27.27$
$-22.22--25$
$-20--22.22$
$-14.29--20$

(c) Growth rate of the unemployment rate

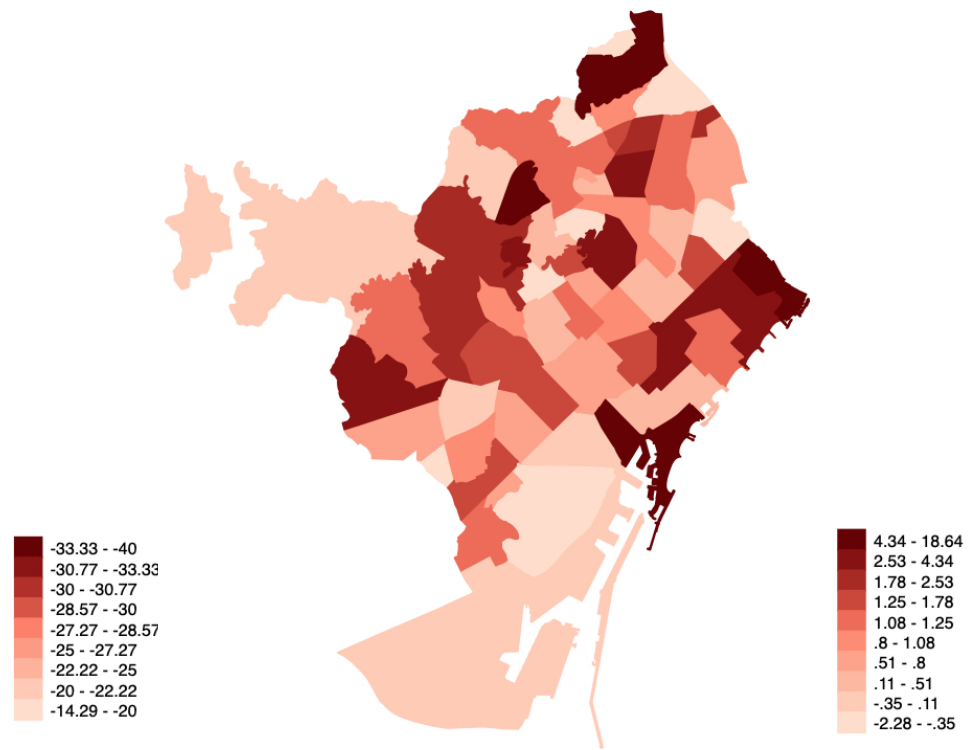

(d) Population density growth rate 
Figure A.5: Average value of the IV and average number of Airbnb listings over the period studied

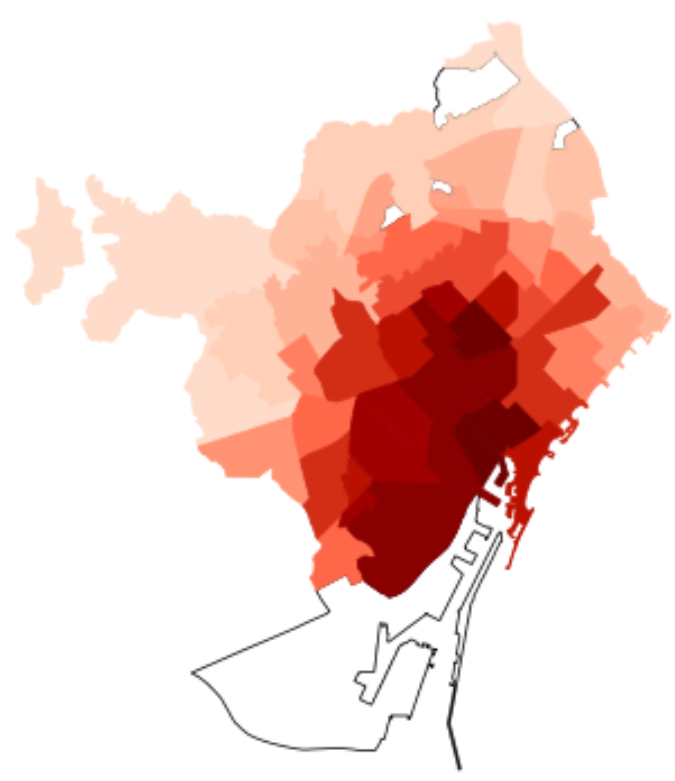

(a) Average $\ln$ (TouristAmenities ${ }_{n} \times$ GoogleTrends $_{t}$ )

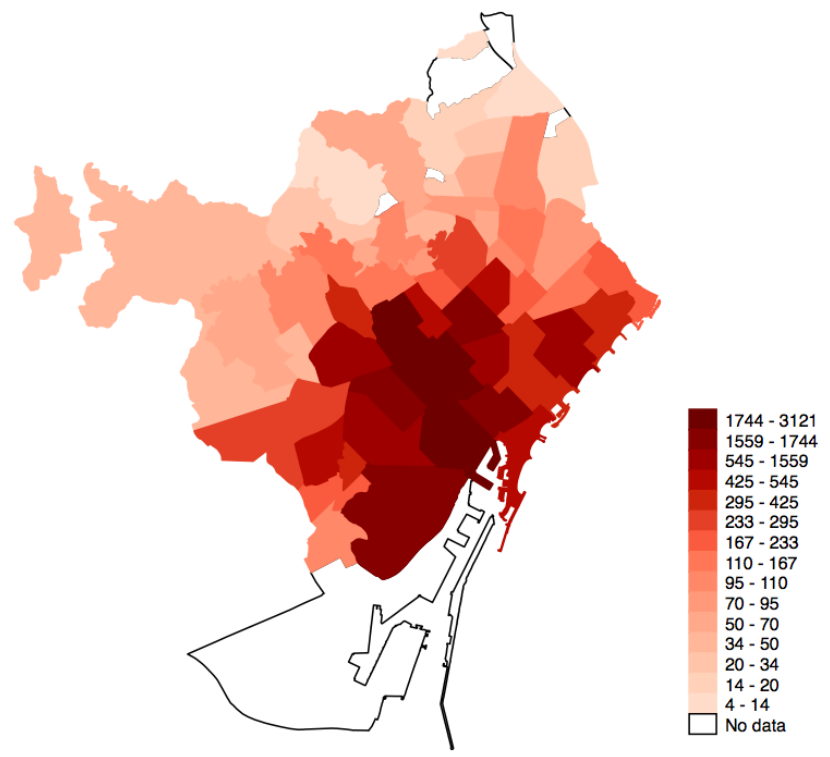

(b) Averge Airbnb activity 
Table 4: Complete regression results

\begin{tabular}{|c|c|c|c|c|c|c|}
\hline \multirow[b]{3}{*}{ Variable } & \multicolumn{3}{|c|}{ Rents, $\ln \left(€ / m^{2}\right)$} & \multicolumn{3}{|c|}{ Prices, $\ln \left(€ / m^{2}\right)$} \\
\hline & (i) & (ii) & (iii) & (i) & (ii) & (iii) \\
\hline & 2SLS & 2SLS & FES2SLS & 2SLS & 2SLS & FES2SLS \\
\hline \multirow[t]{2}{*}{ Airbnb count (x100) } & $0.078^{* * *}$ & $0.021 * * *$ & $0.017^{* * *}$ & $0.051^{*}$ & -0.013 & -0.004 \\
\hline & $(0.023)$ & $(0.006)$ & $(0.006)$ & $(0.029)$ & $(0.019)$ & $(0.014)$ \\
\hline \multirow[t]{2}{*}{ Ln population } & $2.295^{* *}$ & $0.756^{*}$ & $0.736^{* * *}$ & $4.450^{* * *}$ & 0.450 & 0.709 \\
\hline & $(1.134)$ & $(0.386)$ & $(0.302)$ & $(1.113)$ & $(1.573)$ & $(0.821)$ \\
\hline \multirow[t]{2}{*}{ Unemployment } & $-5.424^{* * *}$ & $-2.863^{* * *}$ & $-2.749 * * *$ & $-7.863^{* * *}$ & -1.876 & $-2.156^{*}$ \\
\hline & $(0.764)$ & $(0.612)$ & $(0.575)$ & $(1.194)$ & $(1.696)$ & $(1.181)$ \\
\hline \multirow[t]{2}{*}{ Size of rented $(x 100)$} & -0.028 & $-0.780^{*}$ & $-0.819 * * *$ & $1.280^{* *}$ & -0.174 & -0.138 \\
\hline & $(0.412)$ & $(0.404)^{*}$ & $(0.166)$ & $(0.640)$ & $(0.592)$ & $(0.437)$ \\
\hline \multirow[t]{2}{*}{ Square size (x100) } & -0.000 & 0.003 & $0.003^{* * *}$ & $-0.004^{*}$ & 0.002 & 0.002 \\
\hline & $(0.002)$ & $(0.002)$ & $(0.001)$ & $(0.003)$ & $(0.002)$ & $(0.002)$ \\
\hline \multirow[t]{2}{*}{$\mathrm{W} \cdot \ln (\mathrm{y})$} & - & - & 0.205 & - & & $0.638^{* * *}$ \\
\hline & & & $(0.169)$ & & & $(0.230)$ \\
\hline \multirow[t]{2}{*}{ Rho } & - & - & 0.030 & - & - & $-0.528^{* * *}$ \\
\hline & & & $(0.057)$ & & & $(0.144)$ \\
\hline Observations & 1,005 & 1,005 & 1,005 & 975 & 975 & 975 \\
\hline Neighborhood FE & Yes & Yes & Yes & Yes & Yes & Yes \\
\hline Quarter FE & Yes & Yes & Yes & Yes & Yes & Yes \\
\hline Year FE & No & Yes & Yes & No & Yes & Yes \\
\hline Spatial spillovers & No & No & Yes & No & No & Yes \\
\hline
\end{tabular}

Endogenous: Airbnb count, W·ln $(y)$

Notes: For 2SLS models, reported standard errors are clustered at the neighborhood level. For FES2SLS models, we include spatial lags of the dependent variable and the error structure.

*** $p<0.01,{ }^{* *} p<0.05,{ }^{*} p<0.1$. 
Table 5: Complete impact measures

\begin{tabular}{|c|c|c|c|c|c|c|}
\hline & \multicolumn{3}{|c|}{ Rents, $\ln \left(€ / m^{2}\right)$} & \multicolumn{3}{|c|}{ Prices, $\ln \left(€ / m^{2}\right)$} \\
\hline & ADI & AII & ATI & ADI & AII & ATI \\
\hline \multirow[t]{2}{*}{ Airbnb count (x100) } & $0.0166^{* * *}$ & 0.0042 & $0.0208^{* * *}$ & -0.0037 & -0.0062 & -0.0098 \\
\hline & $(0.0060)$ & $(0.0038)$ & $(0.0064)$ & $(0.0147)$ & $(0.0240)$ & $(0.0385)$ \\
\hline \multirow[t]{2}{*}{ Ln population } & $0.7368^{* *}$ & 0.1886 & $0.9254^{* *}$ & 0.7297 & 1.2294 & 1.9591 \\
\hline & $(0.3027)$ & $(0.2064)$ & $(0.4211)$ & $(0.8487)$ & $(2.0311)$ & $(2.7704)$ \\
\hline \multirow[t]{2}{*}{ Unemployment } & $-2.7535^{* * *}$ & -0.7048 & $-3.4582^{* * *}$ & $-2.2170^{*}$ & -3.7356 & -5.9526 \\
\hline & $(0.5747)$ & $(0.7212)$ & $(0.9579)$ & $(1.2321)$ & $(4.6181)$ & $(5.5116)$ \\
\hline \multirow[t]{2}{*}{ Size of rented (x100) } & $-0.8209^{* * *}$ & -0.2101 & $-1.0310 * * *$ & -0.1417 & -0.2388 & -0.3805 \\
\hline & $(0.1670)$ & $(0.2278)$ & $(0.3278)$ & $(0.4483)$ & $(0.7577)$ & $(1.1929)$ \\
\hline \multirow[t]{2}{*}{ Square size (x100) } & $0.0027^{* * *}$ & 0.0007 & $0.0034^{* * *}$ & 0.0016 & 0.0027 & 0.0044 \\
\hline & $(0.0008)$ & $(0.0008)$ & $(0.0013)$ & $(0.002)$ & $(0.0040)$ & $(0.0057)$ \\
\hline
\end{tabular}

Notes: Reported standard errors are based on the classical delta method. ADI, AII and ATI stand for Average Direct Impact, Average Total Impact and Average Total Impact, respectively.

*** $p<0.01,{ }^{* *} p<0.05,{ }^{*} p<0.1$. 


\section{Bibliography}

Alvarez, I. C., Barbero, J., and Zofío, J. L. (2017). A panel data toolbox for matlab. Journal of Statistical Software.

Anselin, L. (1988). Spatial econometrics: Methods and models. Studies in Operational Regional Science.

Arbia, G., Bera, A. K., Doğan, O., and Taşpınar, S. (2020). Impact measures in spatial autoregressive models. International Regional Science Review, 43(1-2), 40-75.

Ayouba, K., Breuillé, M.-L., Grivault, C., and Le Gallo, J. (2019). Does airbnb disrupt the private rental market? an empirical analysis for french cities. International Regional Science Review, page 016001761882142.

Barron, K., Kung, E., and Proserpio, D. (2018). The sharing economy and housing affordability: Evidence from airbnb. SSRN Electronic Journal.

Calder-Wang, S. (2019). The distributional impact of the sharing economy on the housing market.

Coyle, D. and Yeung, T. Y.-C. (2016). Understanding airbnb in fourteen european cities. The Jean-Jacques Laffont Digital Chair Working Papers.

Drukker, D. M. and Prucha, I. R. (2013). On the $I^{2}(q)$ test statistic for spatial dependence: Finite sample standardization and properties. Spatial Economic Analysis, 8:3, 271-292.

Farronato, C. and Fradkin, A. (2018). The Welfare Effects of Peer Entry in the Accommodation Market: The Case of Airbnb. NBER Working Papers 24361, National Bureau of Economic Research, Inc.

Filippas, A., Horton, J. J., and Zeckhauser, R. J. (2019). Owning, using, and renting: Some simple economics of the "sharing economy". Management Science.

Garcia-López, M., Jofre-Monseny, J., Mazza, R., and Segú, M. (2019). Do short-term rental platforms affect housing markets? evidence from airbnb in barcelona. SSRN Electronic Journal.

Goldsmith-Pinkham, P., Sorkin, I., and Swift, H. (2018). Bartik instruments: What, when, why and how. NBER Working Paper No. 24408.

Hausman, J. (1978). Specification tests in econometrics. Econometrica, 46(6), 1251-1271. 
Horn, K. and Merantea, M. (2017). Is home sharing driving up rents? evidence from airbnb in boston. Journal of Housing Economics, 38.

Horton, J. J. (2015). The tragedy of your upstairs neighbors: Is the airbnb negative externality internalized? arXiv preprint arXiv:1611.05688.

Kapoor, M., Kelejian, H., and Prucha, I. (2007). Panel data models with spatially correlated error components. Journal of Econometrics, Volume 140, Issue 1, 200\%, Pages 97-130, ISSN 0304-4076.

Kelejian, H. and Prucha, I. (1998). A generalized spatial two-stage least squares procedure for estimating a spatial autoregressive model with autoregressive disturbances. The Journal of Real Estate Finance and Economics 17, 99-121 (1998).

Kelejian, H. and Prucha, I. (2001a). A generalized moments estimator for the autoregressive parameter in a spatial model. International Economic Review.

Kelejian, H. and Prucha, I. (2001b). On the asymptotic distribution of the moran $i$ test statistic with applications. Journal of Econometrics, Elsevier, vol. 104(2), pages 219-257, September.

Kelejian, H. and Prucha, I. (2007). Hac estimation in a spatial framework. Journal of Econometrics, 140:131-154.

Koster, H., van Ommeren, J., and Volkhausen, N. (2018). Short-term rentals and the housing market: Quasi-experimental evidence from airbnb in los angeles.

Le Sage, J. and Kelley, R. (2009). Introduction to spatial econometrics. Chapman and Hall/CRC. ISBN 978142006424\%.

Lee, D. (2016). How airbnb short-term rentals exacerbate los angeles's affordable housing crisis: Analysis and policy recommendations. Harv. L. E Pol'y Rev., 10:229.

Lee, L.-F. (2007). Gmm and 2sls estimation of mixed regressive, spatial autoregressive models. Journal of Econometrics, Volume 137, Issue 2, 2007, Pages 489-514,.

LeSage, J. P. and Dominguez, M. (2012). The importance of modeling spatial spillovers in public choice analysis. Public Choice, 150(3-4):525-545.

Mutl, J. and Pfaffermayr, M. (2011). The hausman test in a cliff and ord panel model. The Econometrics Journal, Vol. 14, Issue 1, pp. 48-76, 2011. 
Olea, J. and Pflueger, E. (2013). A robust test for weak instruments. Journal of Business and Economic Statistics 31, 358-369.

Piras, G. (2013). Efficient gmm estimation of a cliff and ord panel data model with random effects. Spatial Economic Analysis, 8:3, 370-388.

Valentin, M. (2019). The effects of regulating the housing short-term rental market: Evidence from new orleans. Available at SSRN 3329964.

Wachsmuth, D. and Weisler, A. (2018). Airbnb and the rent gap: Gentrification through the sharing economy. Environment and Planning A: Economy and Space, 50(6):1147-1170.

Zervas, G., Proserpio, D., and Byers, J. W. (2017). The rise of the sharing economy: Estimating the impact of airbnb on the hotel industry. Journal of marketing research, 54(5):687705. 